University of Wollongong

Research Online

Faculty of Engineering and Information

Faculty of Engineering and Information

Sciences - Papers: Part B

Sciences

2020

\title{
A comprehensive numerical analysis of cross-flow vortex-induced vibrations for top tension risers under different flows
}

Guijie Liu

Haiyang Li

Zhaozun Qiu

Zhixiong Li

University of Wollongong, lizhixio@uow.edu.au

Follow this and additional works at: https://ro.uow.edu.au/eispapers1

Part of the Engineering Commons, and the Science and Technology Studies Commons

Research Online is the open access institutional repository for the University of Wollongong. For further information contact the UOW Library: research-pubs@uow.edu.au 


\title{
A comprehensive numerical analysis of cross-flow vortex-induced vibrations for top tension risers under different flows
}

\author{
Abstract \\ In this paper, the cross-flow vortex-induced vibration (VIV) response of a top tension riser under different \\ flow fields are comprehensively studied using a numerical simulation model based on time domain \\ analysis. A semi-empirical time-domain analysis model that considers the fluid-structure interaction \\ problem in the riser vibration process is proposed and verified by comparison with the previous \\ experimental results. The influence of the flow velocity, the spanwise length of the flow field, and other \\ factors on the VIV amplitude and frequency characteristics of the riser is analyzed in detail. The results \\ show that the VIV response of the riser exhibits obvious multi-modal characteristics, which are \\ accompanied by modal transition, lock-in vibration, synchronous vibration, etc., and the region where the \\ lock-in or synchronous vibration occurs is exactly the region where the crest of the amplitude curve \\ locates. Besides, the VIV intensity of the riser in the stepped flow and uniform flow fields show a tendency \\ of fluctuating increase with the increase of the flow velocity and spanwise length of the flow field, while \\ the VIV intensity of the riser in shear flow is positively correlated with the flow velocity and spanwise \\ length of the flow field. The present study may provide a reference for the prediction of VIV of marine riser \\ in the complex current environment.

\section{Disciplines} \\ Engineering | Science and Technology Studies

\section{Publication Details} \\ Liu, G., Li, H., Qiu, Z. \& Li, Z. (2020). A comprehensive numerical analysis of cross-flow vortex-induced \\ vibrations for top tension risers under different flows. Physics of Fluids, 32 (2), 027102-1-027102-21.
}




\title{
A comprehensive numerical analysis of cross-flow vortex-induced vibrations for top tension risers under different flows
}

\author{
Cite as: Phys. Fluids 32, 027102 (2020); doi: 10.1063/1.5139545 \\ Submitted: 23 November 2019 • Accepted: 26 January 2020 • \\ Published Online: 11 February 2020

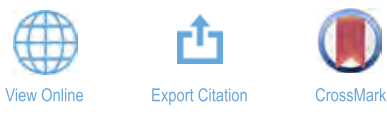

Guijie Liu (刘贵杰), ${ }^{1,2, a)}$ (D) Haiyang Li (李海洋), ${ }^{1,2}$ Zhaozun Qiu (邱兆尊), ${ }^{1,2}$ and Zhixiong Li (李志雄) ${ }^{1,3}$

\begin{abstract}
AFFILIATIONS
${ }^{1}$ Department of Mechanical and Electrical Engineering, Ocean University of China, Qingdao 266100, China

${ }^{2}$ Key Laboratory of Ocean Engineering of Shangdong Province, Ocean University of China, Qingdao 266100, China

${ }^{3}$ School of Mechanical, Materials, Mechatronic and Biomedical Engineering, University of Wollongong, Wollongong, NSW 2522, Australia
\end{abstract}

a) Author to whom correspondence should be addressed: liuguijie@ouc.edu.cn

\begin{abstract}
In this paper, the cross-flow vortex-induced vibration (VIV) response of a top tension riser under different flow fields are comprehensively studied using a numerical simulation model based on time domain analysis. A semi-empirical time-domain analysis model that considers the fluid-structure interaction problem in the riser vibration process is proposed and verified by comparison with the previous experimental results. The influence of the flow velocity, the spanwise length of the flow field, and other factors on the VIV amplitude and frequency characteristics of the riser is analyzed in detail. The results show that the VIV response of the riser exhibits obvious multi-modal characteristics, which are accompanied by modal transition, lock-in vibration, synchronous vibration, etc., and the region where the lock-in or synchronous vibration occurs is exactly the region where the crest of the amplitude curve locates. Besides, the VIV intensity of the riser in the stepped flow and uniform flow fields show a tendency of fluctuating increase with the increase of the flow velocity and spanwise length of the flow field, while the VIV intensity of the riser in shear flow is positively correlated with the flow velocity and spanwise length of the flow field. The present study may provide a reference for the prediction of VIV of marine riser in the complex current environment.
\end{abstract}

Published under license by AIP Publishing. https://doi.org/10.1063/1.5139545

\section{INTRODUCTION}

Marine riser is a pivotal part to connect the underwater production equipment and the floating platform in marine oil and gas production systems, and is always subjected to a combination of excitations from wind, waves, ${ }^{1}$ and currents, causing the vortexinduced vibration (VIV) of marine risers. ${ }^{2}$ The VIV is the main factor causing fatigue damage of the marine riser, which seriously threatens the operational safety of marine oil and gas production systems. Many researchers have conducted extensive research on VIV. In recent years, many review articles have introduced the progress of research on VIV phenomena, such as Bearman, ${ }^{3}$ Williamson and Govardhan, ${ }^{4,5}$ Gabbai and Benaroya, ${ }^{6}$ and more recently, Xue et al. ${ }^{7}$ and Hong and Shah. ${ }^{8}$ Therefore, it is necessary to study the VIV response characteristics of the risers in the complex flow field. Some key parameters commonly used in studying VIV are listed in
Table I. ${ }^{9}$ The flow field profile is the key factor affecting the VIV characteristics of the riser, in which the flow velocity and the spanwise length of the flow field are the two basic elements of the flow field profile. The difference in the flow velocity and the spanwise length of the flow field will change the profile of the flow field, such as the uniform flow field, stepped flow field, shear flow field, and composite flow field, which will cause different VIV responses of the riser. Most of the previous studies have focused on relatively single flow field environments such as uniform flow fields or linear shear flow field, ignoring the relationship between different flow fields. As the marine oil and gas production system gradually turns to the deep sea, ${ }^{10}$ the flow field in the marine environment becomes more diverse. Therefore, this paper comprehensively studies the VIV response characteristics of a top tension riser under different flow field profiles such as the uniform flow field, stepped flow field, shear flow field, and composite flow field. 
TABLE I. Key parameters.

\begin{tabular}{lcc}
\hline \hline Parameters & Symbol & Expression \\
\hline Mass ratio & $\mathrm{M}^{*}$ & $\frac{\mathrm{m}}{\pi \rho D^{2} L / 4}$ \\
Damping ratio & $\xi$ & $\frac{c}{2 \sqrt{k\left(m+m_{A}\right)}}$ \\
Velocity ratio/reduced velocity & $U^{*}$ & $\frac{U}{f_{N} D}$ \\
Amplitude ratio & $\mathrm{A}^{*}$ & $\frac{A}{D}$ \\
Frequency ratio & $f^{*}$ & $\frac{f}{f_{N}}$ \\
Streamwise force coefficient & $C_{d}$ & $\frac{1}{2} \rho U^{2} D L$ \\
(the vortex drag coefficient) & & $\frac{F_{Y}}{1} \rho U^{2} D L$ \\
Transverse force coefficient & $C_{L}$ & $\frac{\rho U D}{\mu}$ \\
the vortex lift coefficient) & & $\frac{L}{D}$ \\
Reynolds number & $R e$ & $/$
\end{tabular}

In order to accurately predict the VIV response of marine risers, reliable empirical data based on experimental tests are essential. During the experiment, it is relatively easy to simulate a uniform flow field ${ }^{11-13}$ or an oscillating flow field ${ }^{14}$ in the water tank by changing the flow velocity of the current or the towing speed of the crane. In order to simulate the shear flow field, Trim et al. ${ }^{15}$ fixed one end of the riser and connected the other end to the crane to move the crane along a specific arc and tow the riser to expose the riser to the shear flow; Lie and Kaasen ${ }^{16}$ fixed the two ends of the riser model on the trailer and the buoy, respectively. The trailer on the dock moves at a specific speed to make the riser model in shear flow. As for the stepped flow field, the main simulation scheme is to place the lower part of the riser in a uniform flow field and the upper part in a still water flow ${ }^{17}$ or in the air. ${ }^{18,19}$

The prediction methods of VIV of marine risers are generally divided into semi-empirical methods and the computational fluid dynamics' (CFD) method. ' In the semi-empirical method, the hydrodynamic vortex-induced force is generally simulated by the wake oscillator model or the experimental data obtained from the forced vibration experiment. The previous linear model may overestimate the modal amplitude of the riser VIV and ignore the interaction between the multi-modal responses. Therefore, many scholars have proposed various nonlinear fluid-solid coupling models in recent years. Srinil ${ }^{20,21}$ established a low-order fluid-solid coupling model for the VIV simulation of vertical and curved flexible cylinders, in which the influence of inclination and tension of the circular tube was considered. They calculated the nonlinear, multi-mode VIV response of the riser, and then studied the cross-flow VIV of variable tension vertical cylinders in the linear shear flow by a timedomain analysis method. Recently, Thorsen et al. ${ }^{22}$ proposed a VIV response prediction model combining a semi-empirical model with a nonlinear finite element model, which can predict the dynamic
VIV response of a riser under different operating conditions, including oscillating flow and nonlinear structural effects. In addition to semi-empirical models, the CFD method is an effective method to study the dynamic response of complex fluid-structure coupled structures. ${ }^{23}$ Ji et al. ${ }^{24}$ simulated the VIV characteristics of the stepped cylinders with different diameter ratios when the Reynolds number was 200 by direct numerical simulation method, and found that the diameter ratio has a great influence on the vibration response and vortex shedding mode of the cylinder. However, the CFD method usually requires high computational power. At present, all CFD models are difficult to directly solve the three-dimensional time domain of the large aspect ratio riser in the complex flow field. ${ }^{25}$ A feasible method to simulate the VIV response of the riser is the strip method, which is a quasi-three-dimensional numerical solution method. ${ }^{26}$ The strip method selects several sections along the axial direction of the riser and uses the CFD method to solve the hydrodynamic force on each section. Based on the strip method, Duanmu et $a .^{27}$ and Fu et al. ${ }^{28}$ developed a viv-FOAM-SJTU solver to simulate the VIV of a slender flexible riser. Sun et al. ${ }^{29}$ proposed a method combining the strip method and discrete vortices' method, and used the finite volume method and the incremental method to calculate the three-dimensional VIV characteristics of flexible risers.

In this paper, the prediction model of the VIV response of top tension risers is established by a time-domain numerical simulation. The flow field profile is the key parameter affecting the VIV response of riser. Hence, the influence of the flow field profile parameters such as the flow velocity and spanwise length of the flow field on the VIV response characteristics of the riser is studied. The main contents of this paper are as follows: First, a semi-empirical time-domain analysis model is proposed in which the fluid-solid coupling problem in the riser vibration process is considered. Second, the proposed numerical model was used to simulate the experimental model in a stepped flow field, and the numerical simulation results were compared with the experimental data to verify the proposed numerical model. Finally, this paper conducted a comprehensive study on VIV of the top tension riser in uniform flow field profile, stepped flow field profile, shear flow field profile, and composite flow field profile, and analyzed the influence of the flow velocity, spanwise length of the flow field, and other factors on the VIV amplitude and frequency characteristics of the riser, which could provide reference data for the prediction of VIV of marine riser in the complex marine environment.

\section{NUMERICAL METHODOLOGY}

\section{A. Structure vibration model}

The riser can be simplified as a simply supported beam pinned at both ends according to the Euler-Bernoulli beam theory. ${ }^{27}$ The $\mathrm{X}$-axis direction is the in-line direction, the $\mathrm{Y}$-axis is the cross-flow direction, and the $\mathrm{Z}$-axis is the axial direction, as shown in Fig. 1. The in-line and cross-flow motion differential equation of the top tension riser can be expressed as follows:

$$
\begin{gathered}
\text { In - line: } m \frac{\partial^{2} x}{\partial t^{2}}+c \frac{\partial x}{\partial t}+E I \frac{\partial^{4} x}{\partial z^{4}}-T \frac{\partial^{2} x}{\partial z^{2}}=f_{x}(z, t), \\
\text { Cross - flow: } m \frac{\partial^{2} y}{\partial t^{2}}+c \frac{\partial y}{\partial t}+E I \frac{\partial^{4} y}{\partial z^{4}}-T \frac{\partial^{2} y}{\partial z^{2}}=f_{y}(z, t),
\end{gathered}
$$




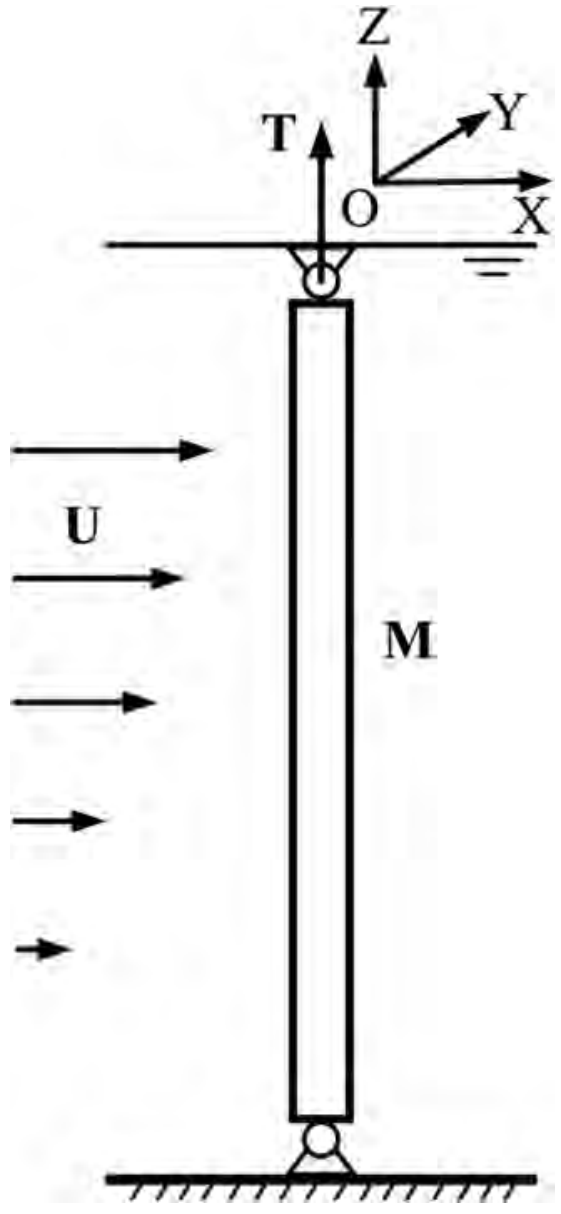

FIG. 1. Schematic diagram of the top tension riser.

where $E I$ is the bending stiffness, $m$ is the effective mass of the riser per unit length, $c$ is the structural damping, $T$ is the effective tension, $f_{x}(z, t)$ and $f_{y}(z, t)$ represent the vortex drag and lift force of the in-line and cross-flow directions, respectively. Among them, the effective mass of the riser can be expressed as ${ }^{3}$

$$
m=m_{r}+m_{f}+m_{a}
$$

where $m_{r}=\rho_{r} \pi\left(D^{2}-d^{2}\right) / 4$ is the mass of riser per unit length, $\rho_{r}$ is the material density of the riser, $D$ and $d$ are the outer diameter and inner diameter of the riser, respectively, $m_{f}=\rho_{f} \pi d^{2} / 4$ is the mass of internal flow per unit length, $\rho_{f}$ is the internal flow density, $m_{a}=C_{m} \rho D^{2} \pi / 4$ is the additional mass, $C_{m}$ is the additional mass coefficient, and $\rho$ is the flow density.

In the actual riser system, since the riser is affected by its own weight, the internal tension of the riser is not evenly distributed, but changes with the water depth so that the effective tension gradually decreases from the top to the bottom of the riser. The effective tension of the riser can be expressed as ${ }^{31,32}$

$$
T(z)=T_{0}-\left[\pi\left(D^{2}-d^{2}\right)\left(\rho_{r}-\rho\right) g / 4\right] z,
$$

where $\mathrm{g}$ is the gravitational acceleration.

\section{B. Hydrodynamic force model}

The hydrodynamic force model was modified based on the classical model. According to the previous research results, the influence of the in-line vibration velocity is considered in the classical vortex lift expression. Besides, the influence of nonlinear damping and inertial force on the hydrodynamic force caused by the vibration of the riser are expressed by the Morison equation. ${ }^{22,33-35}$ The modified expression of the in-line cross-flow hydrodynamic force is as follows: ${ }^{36}$

$$
\begin{aligned}
& F_{D}= \frac{1}{2} C_{L}^{\prime} \rho D\left(U-x^{\prime}\right)^{2} \cos \left(2 \pi f_{s}^{x} t\right) \\
&+\frac{1}{2} C_{D} \rho D\left(U-x^{\prime}\right)\left|U-x^{\prime}\right|+C_{m} \rho \frac{\pi D^{2}}{4} x^{\prime \prime} \\
& F_{L}=\frac{1}{2} C_{L} \rho D\left(U-x^{\prime}\right)^{2} \cos \left(2 \pi f_{s}^{y} t\right)+\frac{1}{2} C_{D} \rho D y^{\prime}\left|y^{\prime}\right|+C_{m} \rho \frac{\pi D^{2}}{4} y^{\prime \prime}
\end{aligned}
$$

where $U$ is the flow field velocity, $x^{\prime}$ and $y^{\prime}$ are the vibration velocity of the in-line and cross-flow directions. $x^{\prime \prime}$ and $y^{\prime \prime}$ is the in-line and cross-flow vibration accelerations. $C_{L}$ is the lift coefficient of the cross-flow, $C_{L}^{\prime}$ is the lift coefficient of the in-line direction, $C_{D}$ is the

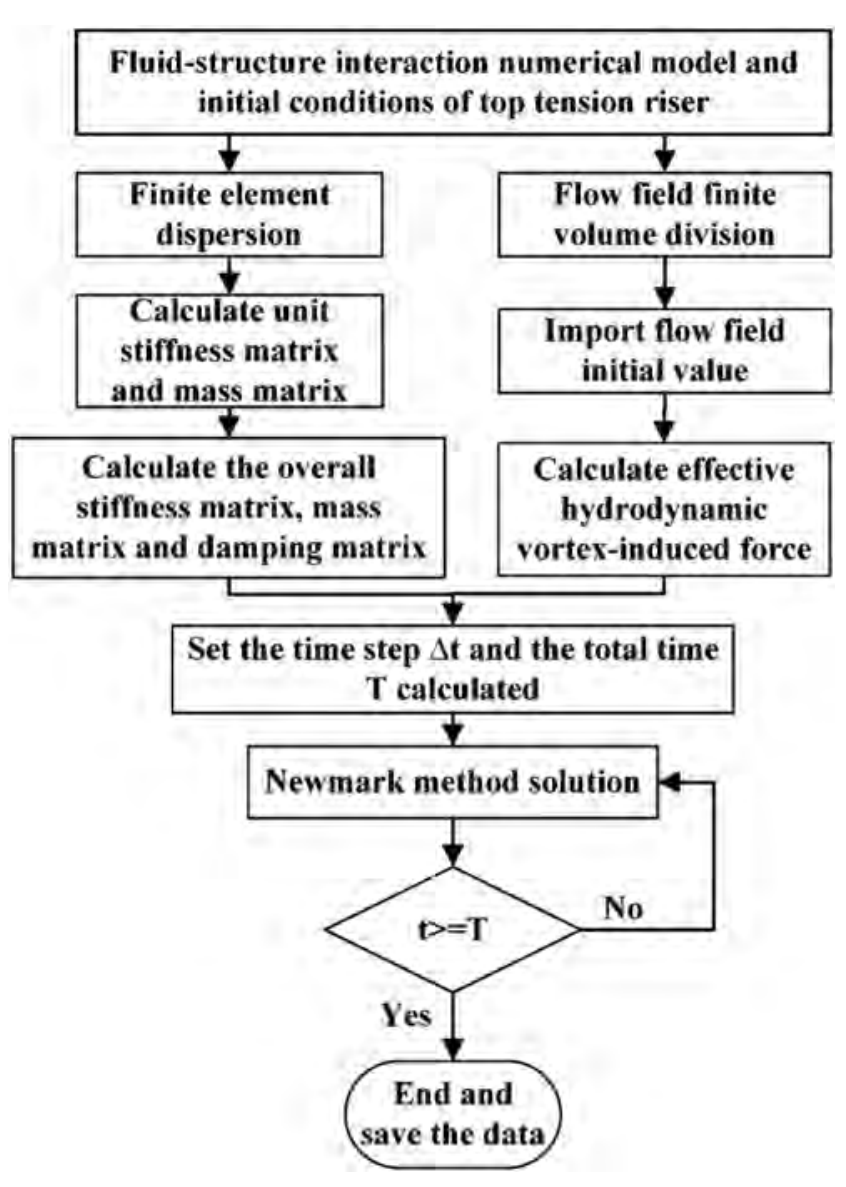

FIG. 2. Calculation process chart of VIV simulation. 
drag coefficient, $\rho$ is the flow density, $D$ is the outer diameter of the riser. $f_{s}$ is the vortex frequency, and its expression is ${ }^{36}$

$$
\begin{aligned}
& \text { IL: } f_{s}^{x}=S_{t}\left(U-x^{\prime}\right) / D, \\
& \text { CF: } f_{s}^{y}=S_{t}\left(U-y^{\prime}\right) / D,
\end{aligned}
$$

where $S_{t}$ is the Strouhal number.

\section{VIV fluid-structure interaction and solution}

The VIV fluid-structure interaction is obtained by the simultaneous riser structural vibration Eqs. (1) and (2) and the hydrodynamic vortex force model (9) and (10). After simplification, the in-line and cross-flow directions, the VIV response equation of the top tension riser can be expressed as follows:

$$
\begin{aligned}
& \text { In - line: }\left(m_{r}+m_{f}\right) \frac{\partial^{2} x}{\partial t^{2}}+c \frac{\partial x}{\partial t}+E I \frac{\partial^{4} x}{\partial z^{4}}-T \frac{\partial^{2} x}{\partial z^{2}} \\
& =\frac{1}{2} C_{L}^{\prime} \rho D\left(U-x^{\prime}\right)^{2} \cos \left(2 \pi f_{s} t\right)+\frac{1}{2} C_{D} \rho D\left(U-x^{\prime}\right)\left|U-x^{\prime}\right|,
\end{aligned}
$$

$$
\begin{gathered}
\text { Cross - flow: }\left(m_{r}+m_{f}\right) \frac{\partial^{2} y}{\partial t^{2}}+c \frac{\partial y}{\partial t}+E I \frac{\partial^{4} y}{\partial z^{4}}-T \frac{\partial^{2} y}{\partial z^{2}} \\
=\frac{1}{2} C_{L} \rho D\left(U-x^{\prime}\right)^{2} \cos \left(2 \pi f_{s} t\right)+\frac{1}{2} C_{D} \rho D y^{\prime}\left|y^{\prime}\right| .
\end{gathered}
$$

Because the riser model is pinned at both ends, its displacements and curvatures are zero. The boundary conditions of the model are ${ }^{30}$ as follows:

$$
\begin{gathered}
\text { In - line: }\left\{\begin{array}{l}
x(0, t)=0 \\
\frac{\partial^{2} x(0, t)}{\partial z^{2}}=0
\end{array},\left\{\begin{array}{l}
x(L, t)=0 \\
\frac{\partial^{2} x(L, t)}{\partial z^{2}}=0
\end{array}\right.\right. \\
\text { Cross - flow: }\left\{\begin{array}{l}
y(0, t)=0 \\
\frac{\partial^{2} y(0, t)}{\partial z^{2}}=0
\end{array},\left\{\begin{array}{l}
y(L, t)=0 \\
\frac{\partial^{2} y(L, t)}{\partial z^{2}}=0
\end{array}\right.\right.
\end{gathered}
$$

In order to solve the fluid-solid coupling equation of VIV of the riser, the equation is discretized by the finite element method (FEM) and then solved by the stepwise integration method. The riser is divided into $\mathrm{N}$ units in the axial direction, and the $\mathrm{N}+1$

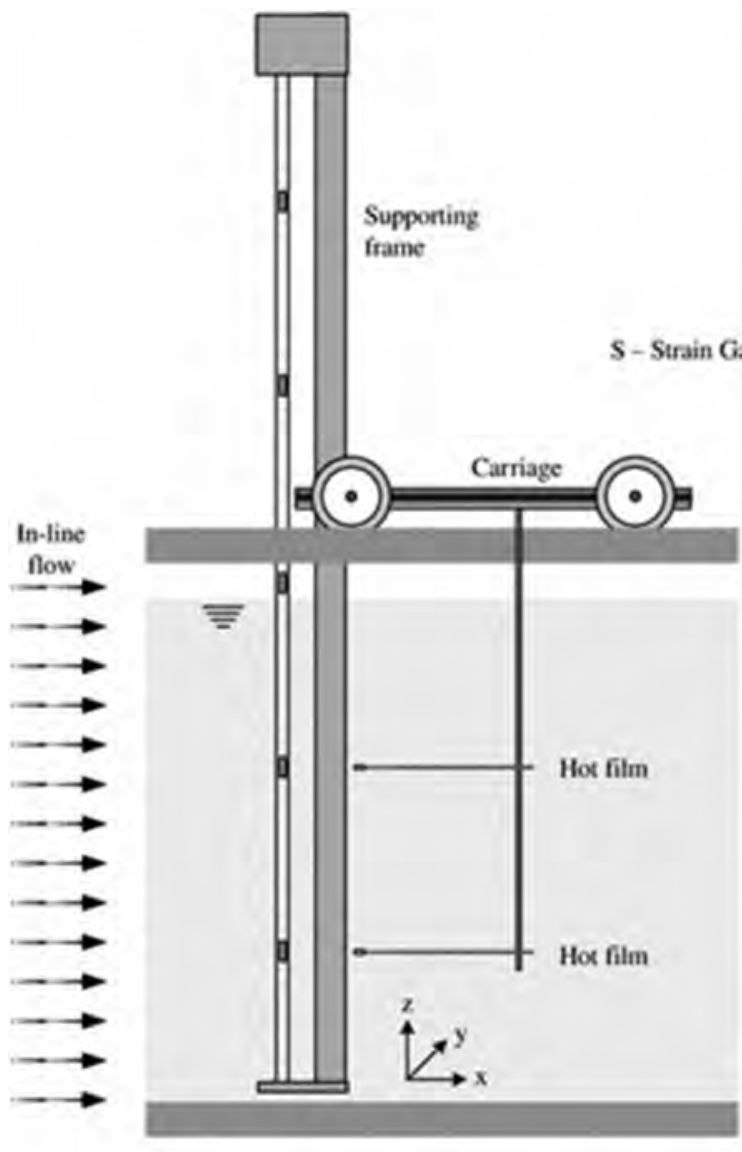

(a)

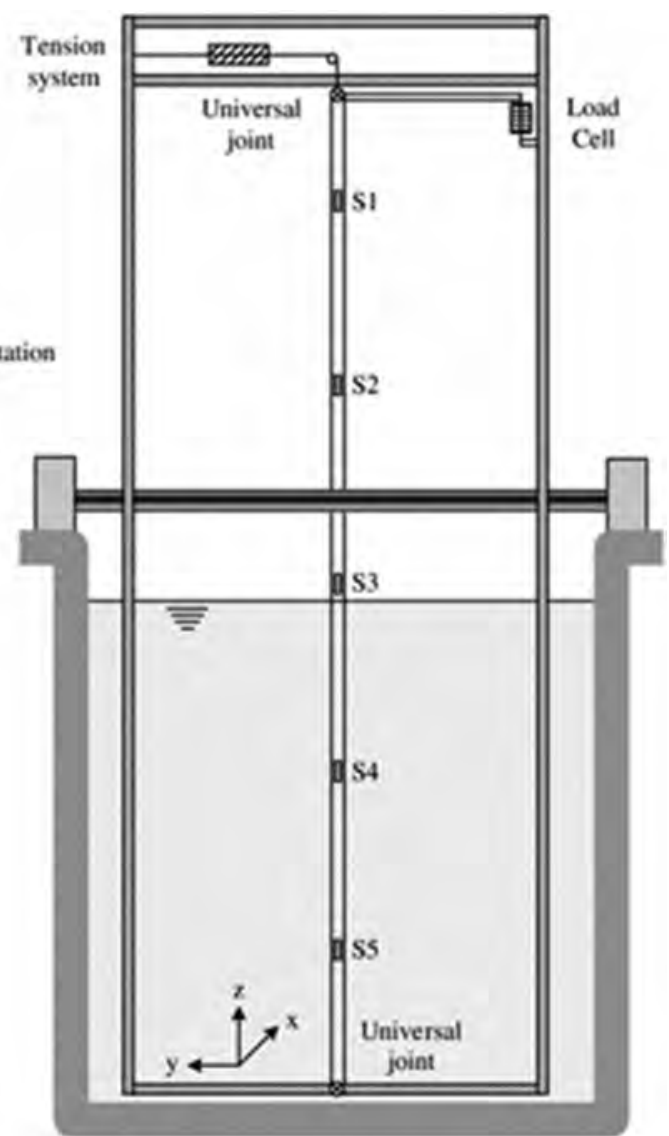

(b)

FIG. 3. The sketch of the experiment setup. (a) Side view of the experimental device; (b) front view of the experimental device. 
node is obtained. The response of each node under the action of the fluid force is calculated, and finally, the overall response of the riser is established. According to the finite element theory, the discrete equation can be expressed as follows:

$$
\begin{aligned}
& \text { In - line: }[M]\left\{x^{\prime \prime}(t)\right\}+[C]\left\{x^{\prime}(t)\right\}+[K]\{x(t)\}=\left\{F_{x}(t)\right\}, \\
& \text { Cross - flow: }[M]\left\{y^{\prime \prime}(t)\right\}+[C]\left\{y^{\prime}(t)\right\}+[K]\{y(t)\}=\left\{F_{y}(t)\right\},
\end{aligned}
$$

where $[M],[C]$, and $[K]$ are the mass matrix, damping matrix, and stiffness matrix, respectively. $\{x(t)\}$ and $\{y(t)\}$ are the in-line and cross-flow nodal displacement vectors, $\left\{F_{x}(t)\right\}$ and $\left\{F_{y}(t)\right\}$ are the in-line and cross-flow hydrodynamic force.

For the nonlinear system of VIV of a top tension riser, the time domain integral method of the Newmark method is used to solve the established numerical simulation model. Based on the Newmark method, the basic formula of the VIV response of the riser at $t+\Delta t$ time can be established. Equation (15) shows the structural dynamics equation at time $t+\Delta t$. Equations (16) and (17) shows the update of the position and velocity of a top tension riser at each time step.

$$
\begin{gathered}
{[M] y^{\prime \prime}{ }_{t+\Delta t}+[C] y^{\prime}{ }_{t+\Delta t}+[K] y_{t+\Delta t}=[F]_{t+\Delta t},} \\
y^{\prime}{ }_{t+\Delta t}=y^{\prime}+\left[(1-\gamma) y_{t}^{\prime \prime}{ }_{t}+\gamma y^{\prime \prime}{ }_{t+\Delta t}\right] \Delta t, \\
y_{t+\Delta t}=y_{t}+y^{\prime}{ }_{t} \Delta t+\left[\left(\frac{1}{2}-\beta\right) y^{\prime \prime}{ }_{t}+\beta y^{\prime \prime}{ }_{t+\Delta t}\right] \Delta t^{2} .
\end{gathered}
$$

Based on the finite element method and the Newmark method, this paper develops the program in Matlab software, ${ }^{38}$ and the calculation process is shown in Fig. 2.

\section{NUMERICAL METHOD VALIDATION}

The VIV experiment of the riser under stepped flow conducted by $\mathrm{Gu}$ et $\mathrm{al} .{ }^{18}$ was carried out in a towing pool with $0.75 \mathrm{~m}$ wide, $0.72 \mathrm{~m}$ high, and $16 \mathrm{~m}$ long at the Federal University of Rio Grande. The total length of the riser model was $1.45 \mathrm{~m}$, of which the length below the water surface was $0.7 \mathrm{~m}$, accounting for $48.3 \%$ of the total length. The stepped flow in the lower part of the riser is simulated by constantly moving the riser model in still water. The sketch of the experimental setup is shown in Fig. 3. The core of the riser model is a steel strip with a diameter of $6.5 \mathrm{~mm}$. The outside of the riser model is wrapped with a plastic tube with a diameter of $19.5 \mathrm{~mm}$ by the support frame. The specific parameters of the riser model are shown in Table II. Twenty strain gauges are installed at five positions of the riser to detect the vibration response of the riser during the experiment, as shown in Fig. 3(b).

Figures 4(a) and 4(b) show the cross-flow displacement timehistory curve and power spectral density (PSD) at the midpoint of the riser with the flow velocity of $0.50 \mathrm{~m} / \mathrm{s}$ during the process of the stepped flow experiment. Figures 4(c) and 4(d) shows the numerical simulation results under the same conditions. By comparing the experimental data with the numerical simulation results, it can be seen that the numerical results are basically consistent with the experimental results in terms of the cross-flow amplitude and frequency at the midpoint of the riser. The amplitude range of the experimental results and numerical simulation results are all
TABLE II. Key parameters of the experiment.

\begin{tabular}{lccc}
\hline \hline Parameters & Symbol & Unit & Value \\
\hline Total length & $L$ & $\mathrm{~m}$ & 1.45 \\
Outer diameter & $D$ & $\mathrm{~m}$ & 0.0195 \\
Submerged length & $L S$ & $\mathrm{~m}$ & 0.70 \\
Bending stiffness & $E I$ & $\mathrm{Nm}^{2}$ & 20.4 \\
Mass ratio & $m^{*}$ & $\ldots$ & 1.55 \\
Aspect ratio & $L / D$ & $\ldots$ & 74.4 \\
Top tension & $T_{\text {top }}$ & $\mathrm{N}$ & $19.6-107.8$ \\
Flow velocity & $U$ & $\mathrm{~m} / \mathrm{s}$ & $0.1-0.98$ \\
Reduced velocity & $U r$ & $\ldots$ & $0-12$ \\
Reynolds number & $\mathrm{Re}$ & $\ldots$ & $1950-19110$ \\
Structural damping & $\xi$ & $\%$ & 3.18 \\
\hline \hline
\end{tabular}

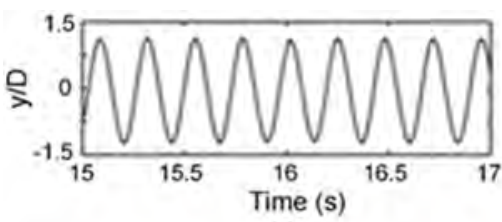

(a)

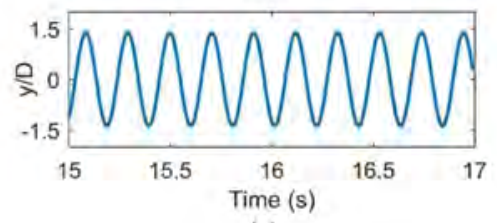

(c)

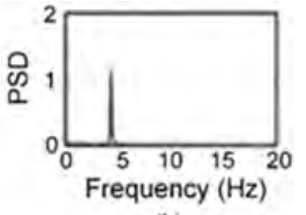

(b)

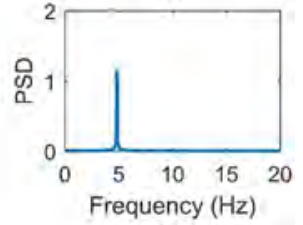

(d)
FIG. 4. The cross-flow time-history curve in an interval $t \in[15,17] \mathrm{s}$ and power spectral density (PSD) at the midpoint of the riser at $T_{\text {top }}=29.4 \mathrm{~N}, U=0.50 \mathrm{~m} / \mathrm{s}$, $U_{r}=4.8, R e=9750$. [(a) and (b)] Experimental results ${ }^{18}$ and [(c) and (d)] present numerical results.

between $[-1.5 \mathrm{D}, 1.5 \mathrm{D}]$, and the vibration frequency of both VIVs is the first-order frequency. Besides, the vibration amplitude and frequency of the numerical simulation is slightly larger than the experimental results, which will also increase the predicted safety factor, thus ensuring the safety of the riser design. Figure 5 shows the crossflow instantaneous deflections of the riser VIV of the experimental results and numerical results with the flow velocity of $0.54 \mathrm{~m} / \mathrm{s}$. It can be seen that the numerical simulation results are also basically consistent with the experimental data that the vibration range is both between $[-1.5 \mathrm{D}, 1.5 \mathrm{D}]$. As a result, the comparison between the above numerical simulation results and the existing experimental results shows that the presented time domain analysis model in this paper can be applied to the VIV prediction of the riser under the steady flow field.

\section{PROBLEM DESCRIPTION}

For the flow field profile factors that affect the VIV response of the riser, the VIV characteristics of the top tension riser model in the uniform flow field, stepped flow field, shear flow field, and composite flow field profile are studied. Table III shows the specific parameters 


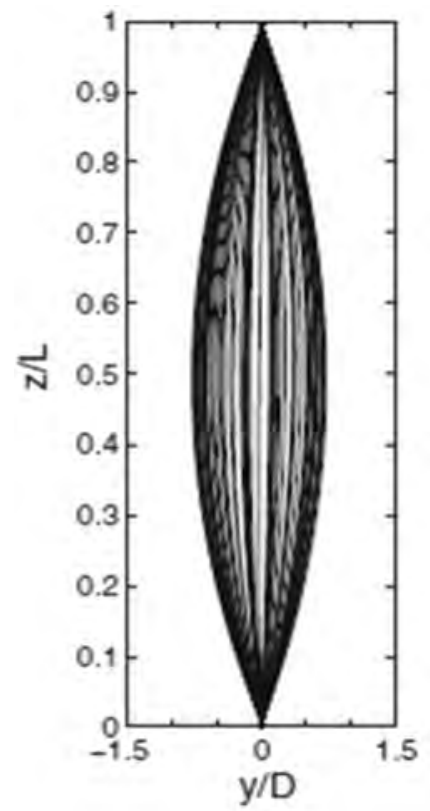

(a)

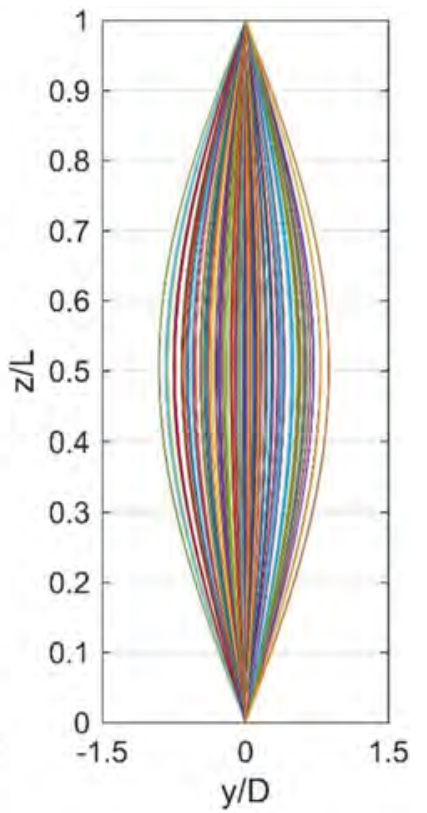

(b)
FIG. 5. Cross-flow instantaneous deflections of the VIV response of the riser at $T_{\text {top }}=29.4 \mathrm{~N}, U=0.54 \mathrm{~m} / \mathrm{s}, U_{r}=5.3$. (a) Experimental results ${ }^{18}$ and (b) present numerical results.

of the riser model. The aspect ratio of the model is $\mathrm{L} / \mathrm{D}=500$, and the mass ratio is $\mathrm{m}^{*}=4.4$. The two ends of the model are pinned and the structural damping $c=0$.

Three representative flow velocities of $0.2 \mathrm{~m} / \mathrm{s}, 0.5 \mathrm{~m} / \mathrm{s}$, and $0.8 \mathrm{~m} / \mathrm{s}$ are selected for the present research. The study of VIV of the riser in the uniform flow field profile is first carried out. Figure 6 shows the uniform flow field profile at different flow velocities of $0.2 \mathrm{~m} / \mathrm{s}, 0.5 \mathrm{~m} / \mathrm{s}$, and $0.8 \mathrm{~m} / \mathrm{s}$. By analyzing the amplitude and frequency characteristics, the VIV response at three different flow velocities were studied and compared, and the effect of the flow velocities of the uniform flow field profile on the cross-flow VIV of the riser was analyzed by making the response intensity map of the riser VIV at different flow velocities.

The VIV study in the stepped flow field is performed next. Table IV shows the different variables studied in the stepped flow field profile. Figure 7 shows the stepped flow field profile at the

TABLE III. Parameters of riser model.

\begin{tabular}{lcc}
\hline \hline Parameter & Symbol & Value \\
\hline Length & $\mathrm{L}$ & $20 \mathrm{~m}$ \\
Outer diameter & $\mathrm{D}$ & $0.04 \mathrm{~m}$ \\
Inner diameter & $\mathrm{d}$ & $0.03 \mathrm{~m}$ \\
Young's modulus & $\mathrm{E}$ & $2.1 \mathrm{e} 10 \mathrm{~Pa}$ \\
Material density & $\rho_{r}$ & $4500 \mathrm{~kg} / \mathrm{m}^{3}$ \\
Seawater density & $\rho$ & $1025 \mathrm{~kg} / \mathrm{m}^{3}$ \\
\hline \hline
\end{tabular}

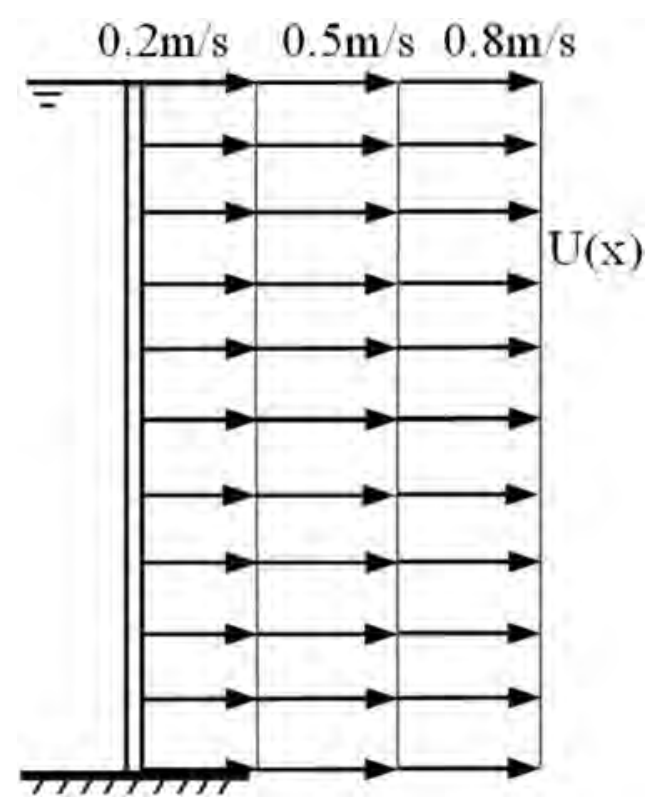

FIG. 6. Schematic diagram of the uniform flow field with different flow velocities.

upper, middle, and lower positions of the riser when the flow rate is $0.5 \mathrm{~m} / \mathrm{s}$. The cross-flow VIV amplitude and the frequency of the riser were analyzed to study the influence of different flow field profile factors such as the flow velocity, position, and spanwise length of flow field on VIV of the top tension riser. First, three kinds of stepped flow fields located on the top of the riser with the spanwise length of $10 \mathrm{~m}$, and the flow velocities of $0.2 \mathrm{~m} / \mathrm{s}, 0.5 \mathrm{~m} / \mathrm{s}$, and $0.8 \mathrm{~m} / \mathrm{s}$, respectively, were studied to investigate the influence of the flow velocity on the VIV response of the riser in the stepped flow field. Then, three kinds of stepped flow fields with a flow velocity of $0.5 \mathrm{~m} / \mathrm{s}$ and a spanwise length of $10 \mathrm{~m}$, located at the upper, middle, and lower part of the riser, respectively, were selected as the research objects to study the influence of the position of the stepped flow field on the VIV response of the riser. Finally, the VIV response characteristics of the riser under the stepped flow field with the flow velocity of $0.5 \mathrm{~m} / \mathrm{s}$ and the spanwise length gradually increasing from the upper part of the riser are studied.

Then, the VIV study in the shear flow field profile is carried out. First, VIV response characteristics of the top tension riser under

TABLE IV. The parameters of the different stepped flow field profile.

\begin{tabular}{lclcc}
\hline \hline Case & $\begin{array}{c}\text { Flow velocity } \\
(\mathrm{m} / \mathrm{s})\end{array}$ & Location & Length $(\mathrm{m})$ & $\begin{array}{c}\text { Flow field } \\
\text { area }\left(\mathrm{m}^{2} / \mathrm{s}\right)\end{array}$ \\
\hline 1 & 0.2 & Upper & 10 & 2 \\
2 & 0.5 & Upper & 10 & 5 \\
3 & 0.8 & Upper & 10 & 8 \\
4 & 0.5 & Middle & 10 & 5 \\
5 & 0.5 & Lower & 10 & 5 \\
6 & 0.5 & Entire & 20 & 10 \\
\hline
\end{tabular}




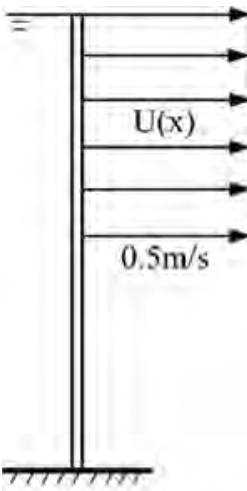

(a)

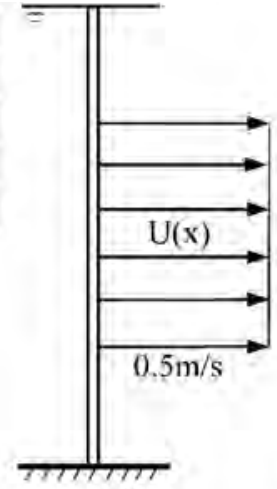

(b)

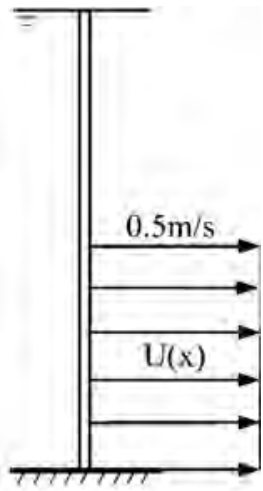

(c)
FIG. 7. Schematic diagram of the different stepped flow field. (a) Upper, (b) middle, and (c) lower.

shear flow with the maximum flow velocities of $0.2 \mathrm{~m} / \mathrm{s}, 0.5 \mathrm{~m} / \mathrm{s}$, $0.8 \mathrm{~m} / \mathrm{s}$, and $1 \mathrm{~m} / \mathrm{s}$ were studied; the flow field diagram is shown in Fig. 8(a). Second, the influence of different spanwise lengths of the flow field on the riser VIV is studied. The maximum flow velocity of the three flow fields is $0.5 \mathrm{~m} / \mathrm{s}$, and the spanwise length is $5 \mathrm{~m}$, $10 \mathrm{~m}$, and $20 \mathrm{~m}$, respectively; the flow field sketch diagram is shown in Fig. 8(b). Finally, the VIV characteristics of the riser when the flow velocity and the spanwise length of flow field increase simultaneously are studied. The flow velocity of the three flow fields are $0.5 \mathrm{~m} / \mathrm{s}, 0.8 \mathrm{~m} / \mathrm{s}$, and $1 \mathrm{~m} / \mathrm{s}$, respectively, while the spanwise lengths are $10 \mathrm{~m}, 16 \mathrm{~m}$, and $20 \mathrm{~m}$, respectively; the flow field sketch diagram is shown in Fig. 8(c). Table $\mathrm{V}$ shows the study parameters for different working conditions for the flow velocity and spanwise length of the shear flow field profile.

Finally, the VIV characteristics of the riser are analyzed in the composite flow field profile, where the composite flow field section is formed by the superposition of multiple simple flow fields in the

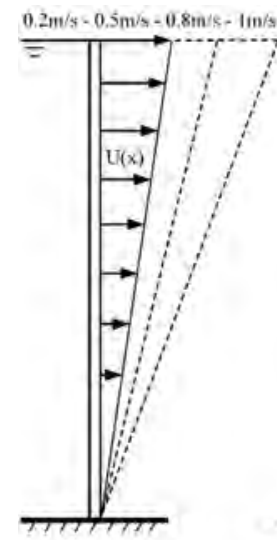

(a)

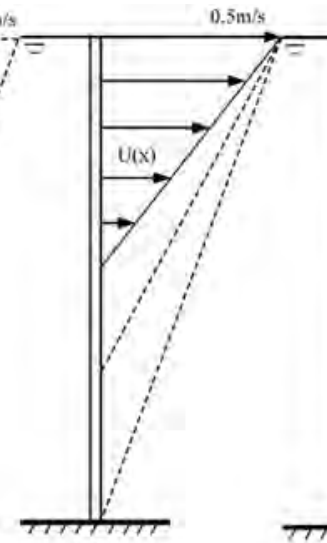

(b)



(c)
FIG. 8. Schematic diagram of the different shear flow field. (a) Different maximum flow velocities of the flow field, (b) different spanwise length of the flow field, and (c) simultaneous increase of the flow velocity and the spanwise length of the flow field.
TABLE V. Parameters of the different shear flow. $U_{\max }$ is the maximum flow velocity of the flow field, $I$ is the span length of the flow field, $k$ is the slope of the flow field, where $k=\| / U_{\max }$.

\begin{tabular}{lcccc}
\hline \hline Case & $U_{\max }(\mathrm{m} / \mathrm{s})$ & $l(\mathrm{~m})$ & $k$ & $\begin{array}{c}\text { Flow field } \\
\text { area }\left(\mathrm{m}^{2} / \mathrm{s}\right)\end{array}$ \\
\hline 1 & 0.2 & 20 & 100 & 2 \\
2 & 0.5 & 20 & 40 & 5 \\
3 & 0.8 & 20 & 25 & 8 \\
4 & 1.0 & 20 & 20 & 10 \\
5 & 0.5 & 5 & 10 & 1.25 \\
6 & 0.5 & 10 & 20 & 2.5 \\
7 & 0.8 & 16 & 20 & 6.4 \\
\hline
\end{tabular}

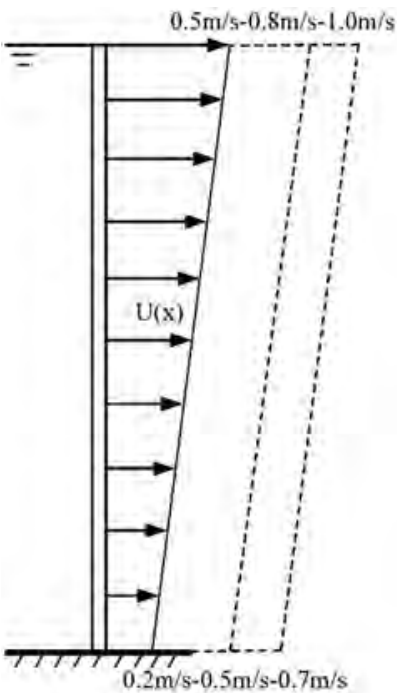

(a)

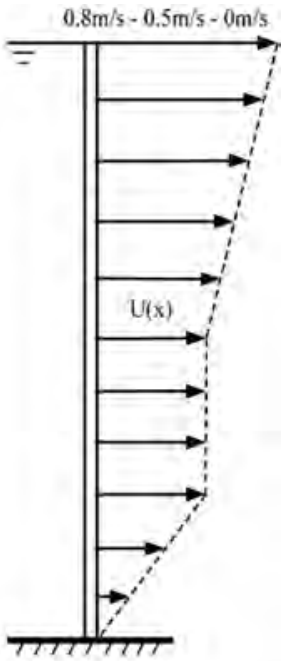

(b)
FIG. 9. Schematic diagram of the composite flow field. (a) The superposition in the forward direction and (b) the superposition in the spanwise direction.

forward direction and in the spanwise direction. The composite flow field is shown in Fig. 9. In the forward superposition of the flow field, the VIV response of the riser in three linear shear flow fields is studied. The maximum flow velocity of these three flow fields are, respectively, $0.5 \mathrm{~m} / \mathrm{s}, 0.8 \mathrm{~m} / \mathrm{s}$, and $1 \mathrm{~m} / \mathrm{s}$, while the corresponding minimum flow velocities are, respectively, $0.2 \mathrm{~m} / \mathrm{s}, 0.5 \mathrm{~m} / \mathrm{s}$, and $0.7 \mathrm{~m} / \mathrm{s}$, as shown in Fig. 9(a). In the spanwise superposition of the flow field, the VIV response of the riser in an irregular flow field profile is studied. The flow velocity of flow field drops from maximum to zero, that is, from maximum $0.8-0.5 \mathrm{~m} / \mathrm{s}$, and finally to $0 \mathrm{~m} / \mathrm{s}$, as shown in Fig. 9(b).

\section{RESULTS AND DISCUSSION}

\section{A. Uniform flow field}

Figure 10 shows the root-mean-square (RMS) amplitude and frequency spatio-temporal plot of the cross-flow VIV response of 


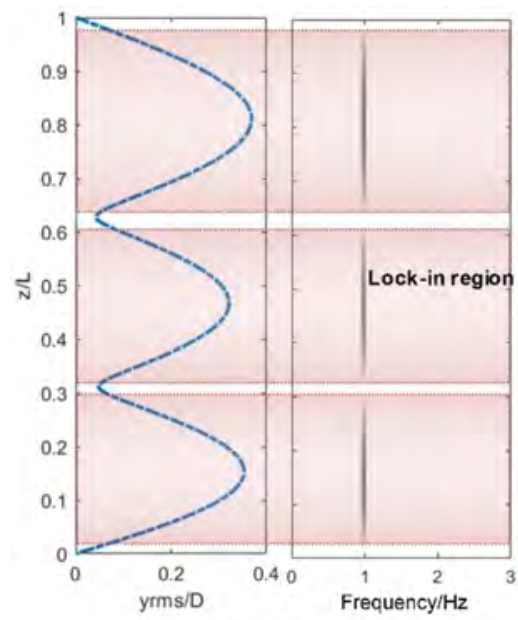

(a) $U=0.2 \mathrm{~m} / \mathrm{s}$

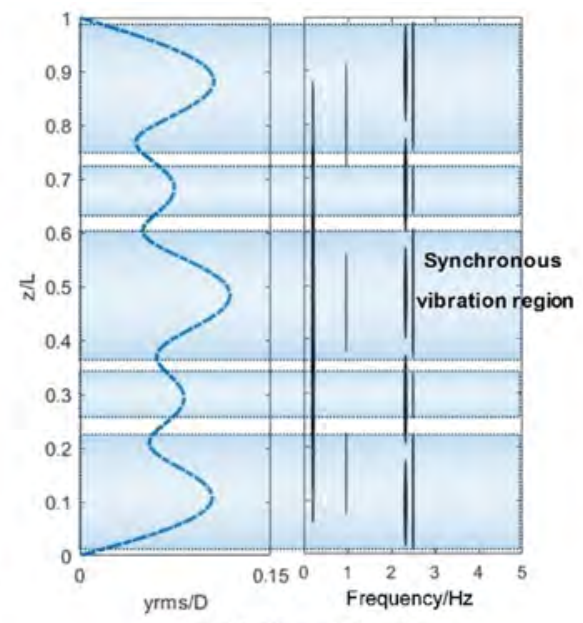

(b) $U=0.5 \mathrm{~m} / \mathrm{s}$

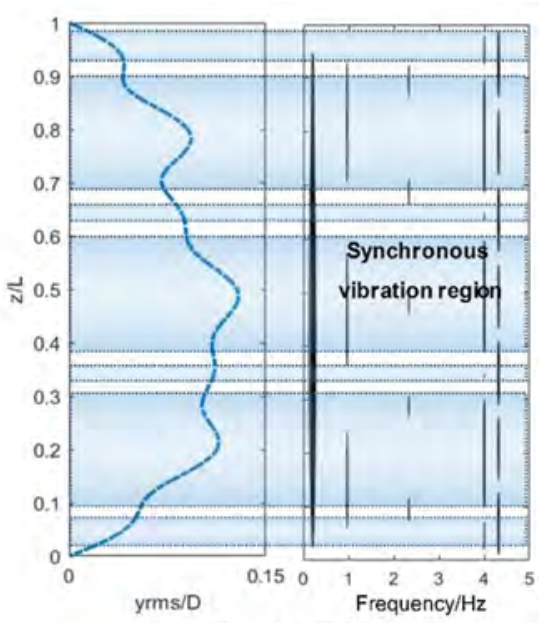

(c) $\mathrm{U}=0.8 \mathrm{~m} / \mathrm{s}$

FIG. 10. RMS amplitude and frequency spatio-temporal plot of cross-flow VIV response of the riser with flow velocities of (a) $0.2 \mathrm{~m} / \mathrm{s}$, (b) $0.5 \mathrm{~m} / \mathrm{s}$, and (c) $0.8 \mathrm{~m} / \mathrm{s}$.

the riser with three flow velocities of $0.8 \mathrm{~m} / \mathrm{s}, 0.5 \mathrm{~m} / \mathrm{s}$, and $0.2 \mathrm{~m} / \mathrm{s}$ (corresponding vortex leakage frequencies are $1 \mathrm{~Hz}, 2.5 \mathrm{~Hz}$, and $4 \mathrm{~Hz}$, respectively), in which the plots show the modes of the third, fifth, and seventh orders, respectively. With the increase of the flow velocity, the mode of VIV of the riser model becomes higher and higher. However, the RMS amplitude value of the riser varies, while the amplitude ratio at a flow velocity of $0.2 \mathrm{~m} / \mathrm{s}$ is significantly higher than that of the other two conditions. Different degrees of synchronous vibration, which refers to the VIV frequency component coincides with the vortex shedding frequency but does not occur lock-in vibration of the riser, occurred in all three flow velocity. Among them, when the flow velocity $\mathrm{U}=0.2 \mathrm{~m} / \mathrm{s}$, the dominant mode of VIV is always occupied by the vortex shedding frequency, and there is no other frequency component. It can be seen that the lock-in vibration obviously occurs so that the amplitude is greatly increased. The synchronous vibration and the lock-in vibration are easy to occur in the uniform flow field, since the entire riser is excited by the same vortex shedding frequency along the span direction, which is beneficial to synchronous vibration and even different degrees of lock-in vibration.

Figure 10 also shows that the region where the lock-in or synchronous vibration occurs is the region where the peak of the amplitude curve is located, and when the frequency is not lock-in, the increase of the frequency component is beneficial to the increase of the amplitude, especially the increase of the minimum amplitude. Each frequency component affects the intensity of the VIV response. The influence of the vortex shedding frequency is the largest, which determines the position and magnitude of the maximum amplitude; the low-order frequency, especially the first-order natural frequency, determines the magnitude of the minimum amplitude. The amplitude and frequency of VIV of the riser at the position of the minimum amplitude are relatively small, and the vibration frequency is very different from the vortex shedding frequency. Because the vibration frequency is low, its closeness to the low-order, especially the first-order natural frequency of the riser will determine the relative magnitude of the minimum amplitude. When the vibration frequency is close to the low-order, especially the first-order natural frequency, it will cause a certain degree of resonance in the riser so that the amplitude minimum value will be relatively large. In addition, the cross-flow vibration response in the uniform flow field shows a certain symmetry when the center of symmetry is a point below the midpoint of the riser. The reason why the center of symmetry is below the midpoint is that the axial tension of the riser from the top to bottom is gradually reduced due to factors such as the wet weight of the riser, so the riser is more and more susceptible to the influence of vortex-induced lift force and thus produces larger VIV response.

Figure 11 shows the spatio-temporal plot of the cross-flow VIV response of the top tension riser with the flow velocity of $U=0.5 \mathrm{~m} / \mathrm{s}$ and $U=0.8 \mathrm{~m} / \mathrm{s}$. It can be seen that the VIV response in the uniform flow field exhibits multi-modal characteristics, in which a significant modal transition phenomenon occurs during the vibration process, and modal conversion is performed according to a certain period. As shown in Fig. 11(a), the transition from the fifth-order mode to the first-order mode starts from $33 \mathrm{~s}$, returns to the stable fifth-order mode at $36 \mathrm{~s}$, and then begins to perform modal conversion at $39 \mathrm{~s}$; the modal conversion period in Fig. 11(b) is shorter. Hence, it can be seen that the VIV of the riser in the uniform flow field exhibits periodic characteristics and a certain symmetry both in space and in time.

Figure 12 shows the vibration response during the flow velocity from $0.1 \mathrm{~m} / \mathrm{s}$ to $1 \mathrm{~m} / \mathrm{s}$ with the interval of $0.1 \mathrm{~m} / \mathrm{s}$. It can be seen that the vibration range is consistent with the variation trend of the extreme amplitude. If the mutation at $0.2 \mathrm{~m} / \mathrm{s}$ is not taken into account, the vortex-induced vibration intensity of the model presents a trend of rising fluctuation, rather than a simple linear change. When the lock-in vibration is not considered, the amplitude and fluctuation frequency of the vortex-induced lift due to vortex shedding will increase with the increase of flow velocity, and the 


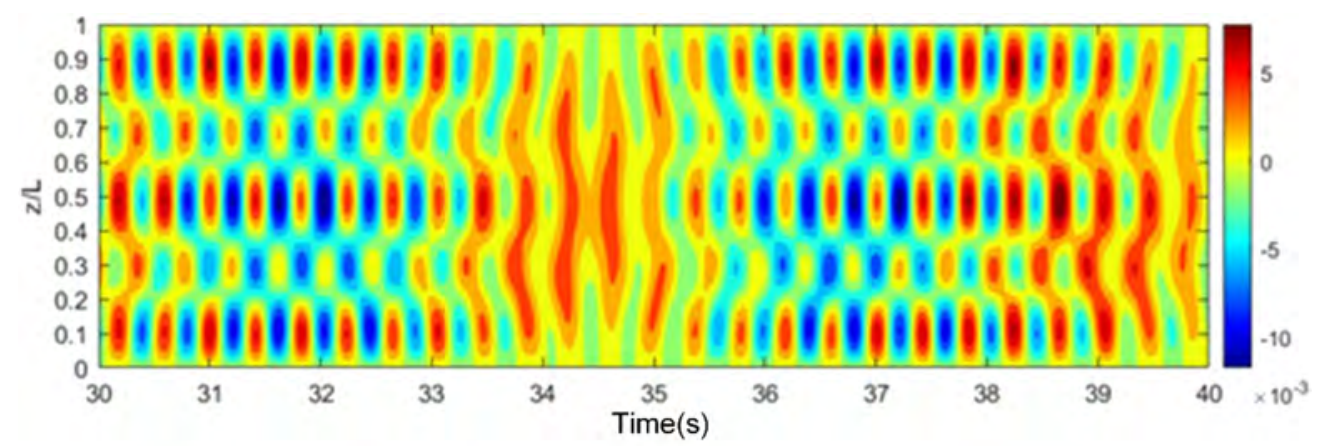

(a)

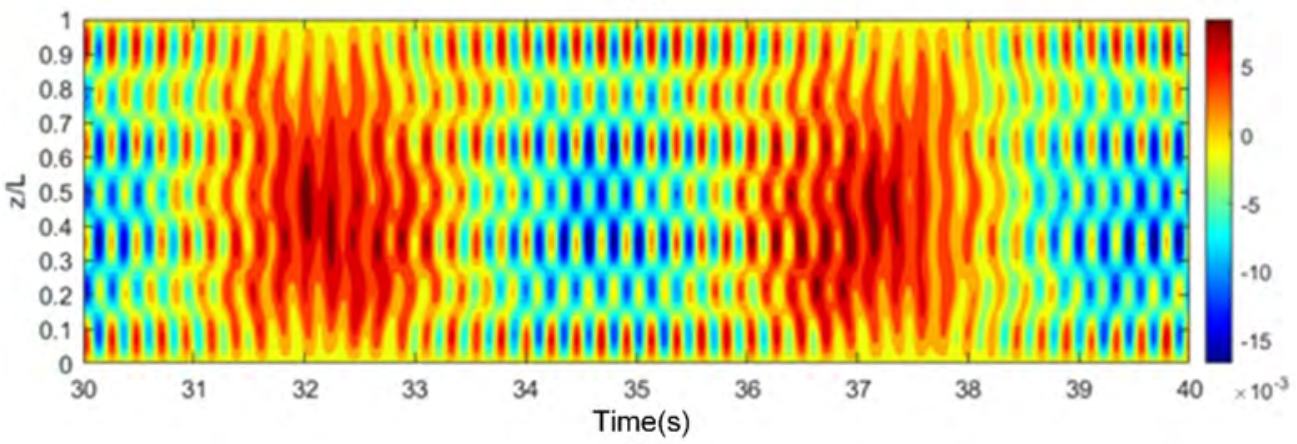

(b)

FIG. 11. Spatio-temporal contour plot of cross-flow vibration of the riser with a velocity of (a) $U=0.5 \mathrm{~m} / \mathrm{s}$ and (b) $U=0.8 \mathrm{~m} / \mathrm{s}$.

intensity of VIV of the riser will also increase with the increase of the vortex-induced force and frequency of the riser. Moreover, when the vortex-induced lift frequency increases, it will occasionally coincide with the natural frequency of a certain order of the riser, causing lock-in vibration or a certain degree of synchronous vibration, which will suddenly increase the intensity of the VIV of the riser. When the vortex shedding frequency exceeds the natural frequency of the riser, the VIV intensity of the riser will decrease relatively.

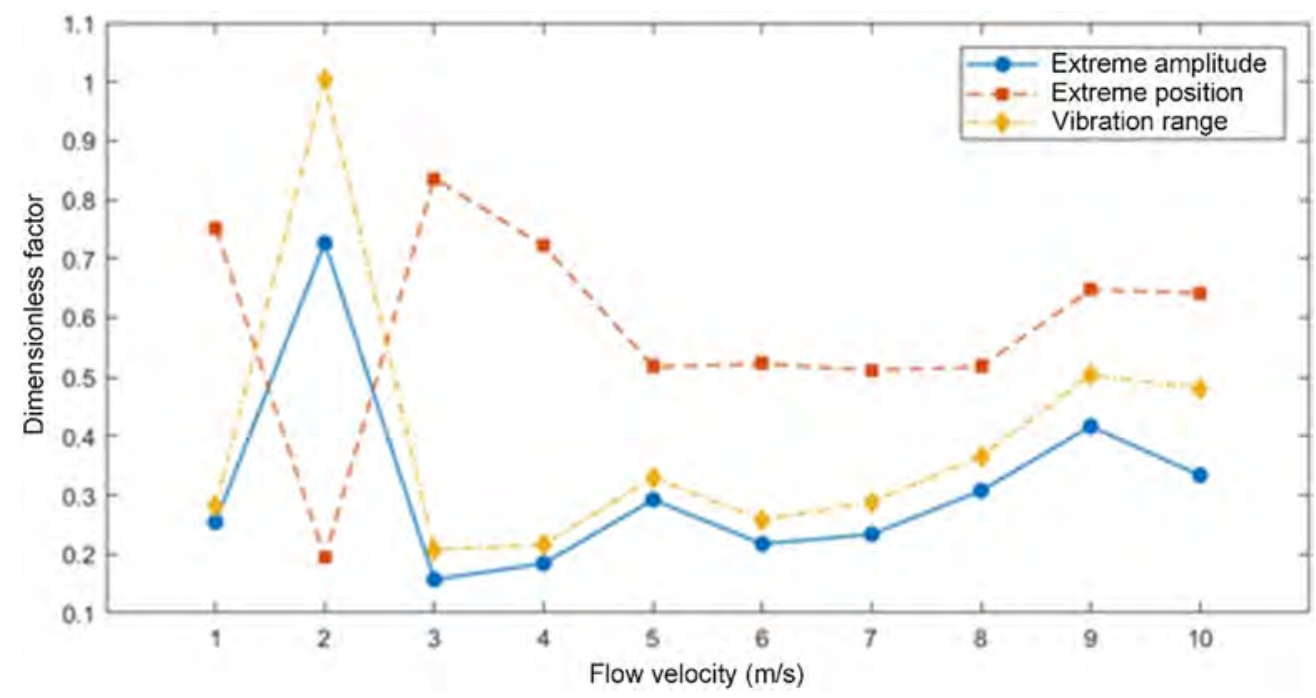

FIG. 12. The trend diagram of the vibration response against the flow velocity where the "vibration range" refers to the range covered by the maximum amplitude envelope of the model vibration. 


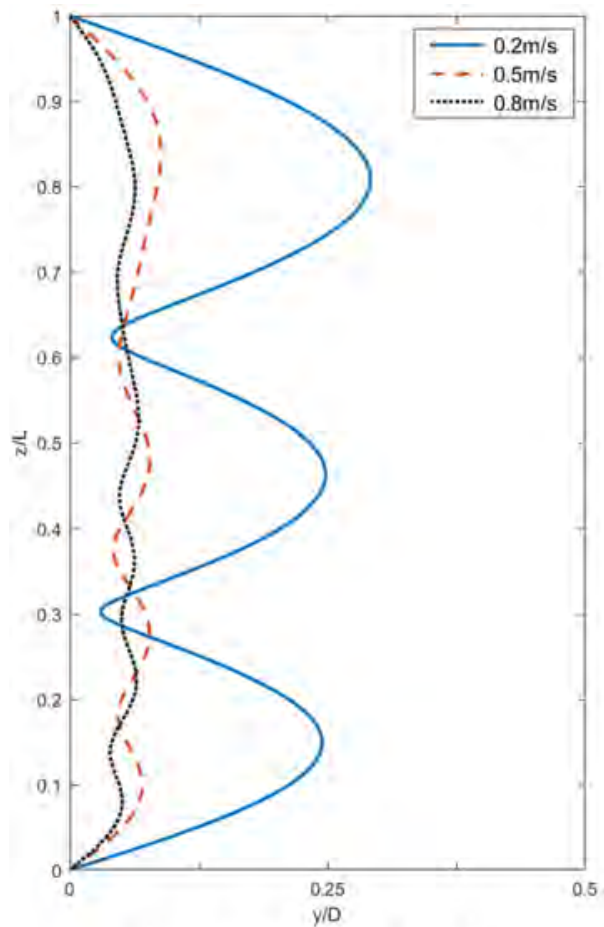

(a) Stepped flow field

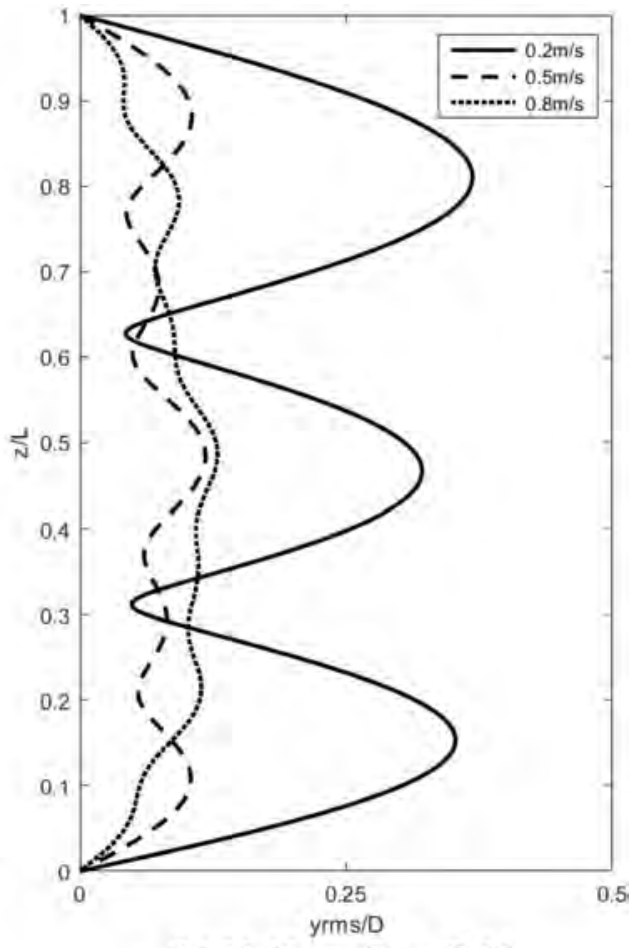

(b) Uniform flow field
FIG. 13. RMS amplitude curve of crossflow VIV response of the riser in two flow field profiles. (a) Stepped flow field, (b) uniform flow field with the span length of $10 \mathrm{~m}$ and flow velocities of $0.2 \mathrm{~m} / \mathrm{s}, 0.5$ $\mathrm{m} / \mathrm{s}$, and $0.8 \mathrm{~m} / \mathrm{s}$ at the upper part of the riser.
In general, the VIV intensity of the riser indicates that fluctuations rise with the increase of the flow velocity. In addition, it can also be seen that amplitude extreme points may appear at various locations in the riser.

\section{B. Stepped flow field}

Figure 13 shows the RMS amplitude of the cross-flow VIV displacement of the riser with three stepped flow fields of which

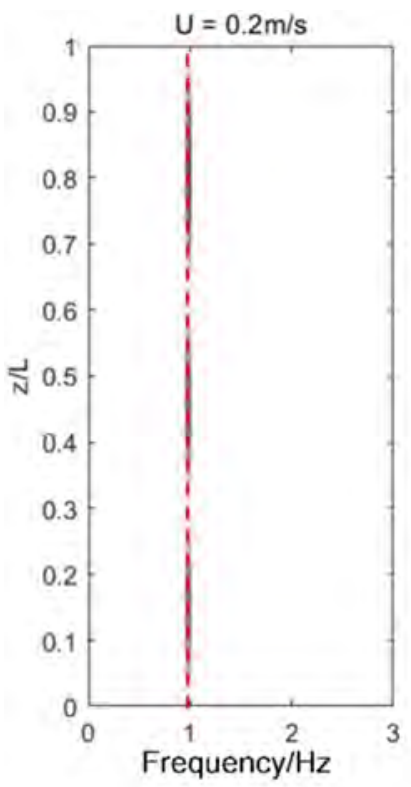

(a)

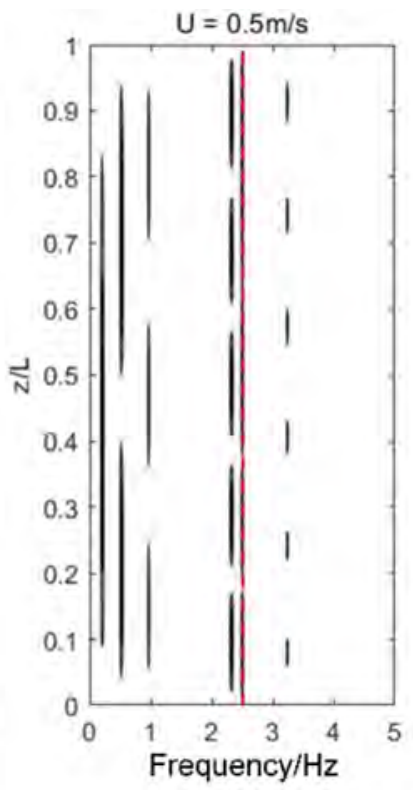

(b)

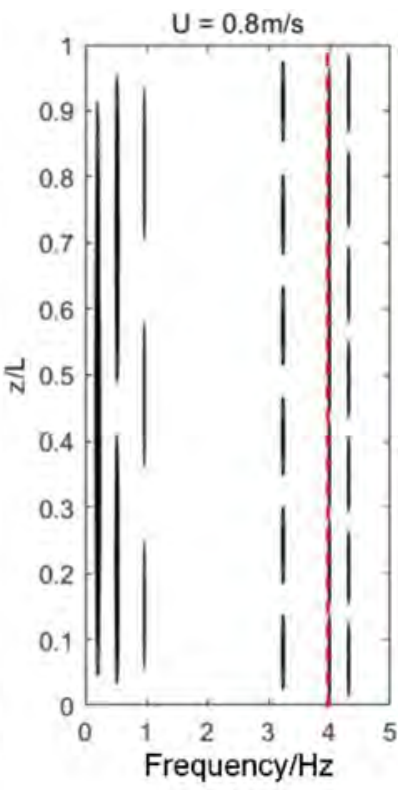

(c)
FIG. 14. The frequency spatio-temporal plot of the cross-flow VIV response of the riser in the stepped flow field with the span length is $10 \mathrm{~m}$ and flow velocities are (a) $0.2 \mathrm{~m} / \mathrm{s}$, (b) $0.5 \mathrm{~m} / \mathrm{s}$, and (c) 0.8 $\mathrm{m} / \mathrm{s}$ at the upper part of the riser. 
the span length is $10 \mathrm{~m}$ and flow velocities are $0.2 \mathrm{~m} / \mathrm{s}, 0.5 \mathrm{~m} / \mathrm{s}$, and $0.8 \mathrm{~m} / \mathrm{s}$ at the upper part of the riser. It can be seen that the curves exhibit third-order, fourth-order, and fifth-order mode shapes, respectively, which are very similar to those in a uniform flow field. With the increase of the flow velocity, the VIV modes are getting higher and higher, while the amplitude of vibration fluctuates with the flow velocity. The reason is the same as that of the riser in a uniform flow field. When the lock-in vibration is not considered, the amplitude and fluctuation frequency of the vortex-induced lift due to vortex shedding will increase with the increase of the flow velocity, and the intensity of VIV of the riser will also increase with the increase of the vortex-induced force and the frequency of the riser. Moreover, when the vortex-induced lift frequency increases, it will occasionally coincide with the natural frequency of a certain order of the riser, causing lock-in vibration or a certain degree of synchronous vibration, which will suddenly increase the intensity of the VIV of the riser. When the vortex shedding frequency exceeds the natural frequency of the riser, the VIV intensity of the riser will decrease relatively. In general, the VIV intensity of the riser indicates that fluctuations rise with the increase of the flow velocity. However, due to the difference of the flow field spanwise length along the risers, the amplitude and the number of VIV modes in the stepped flow (a)

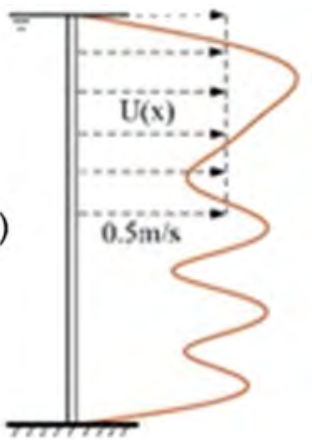

(b)

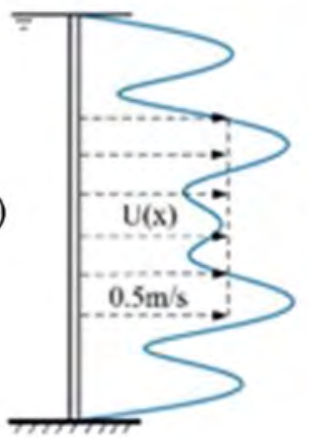

(c)

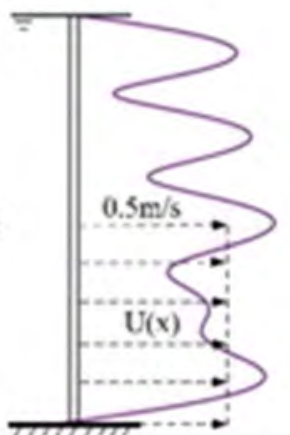

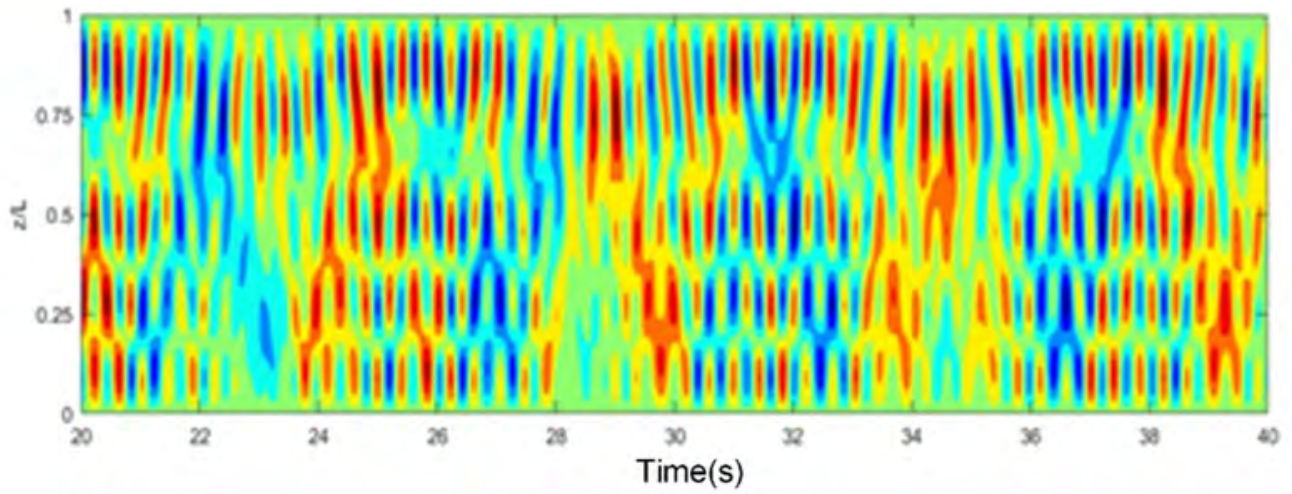
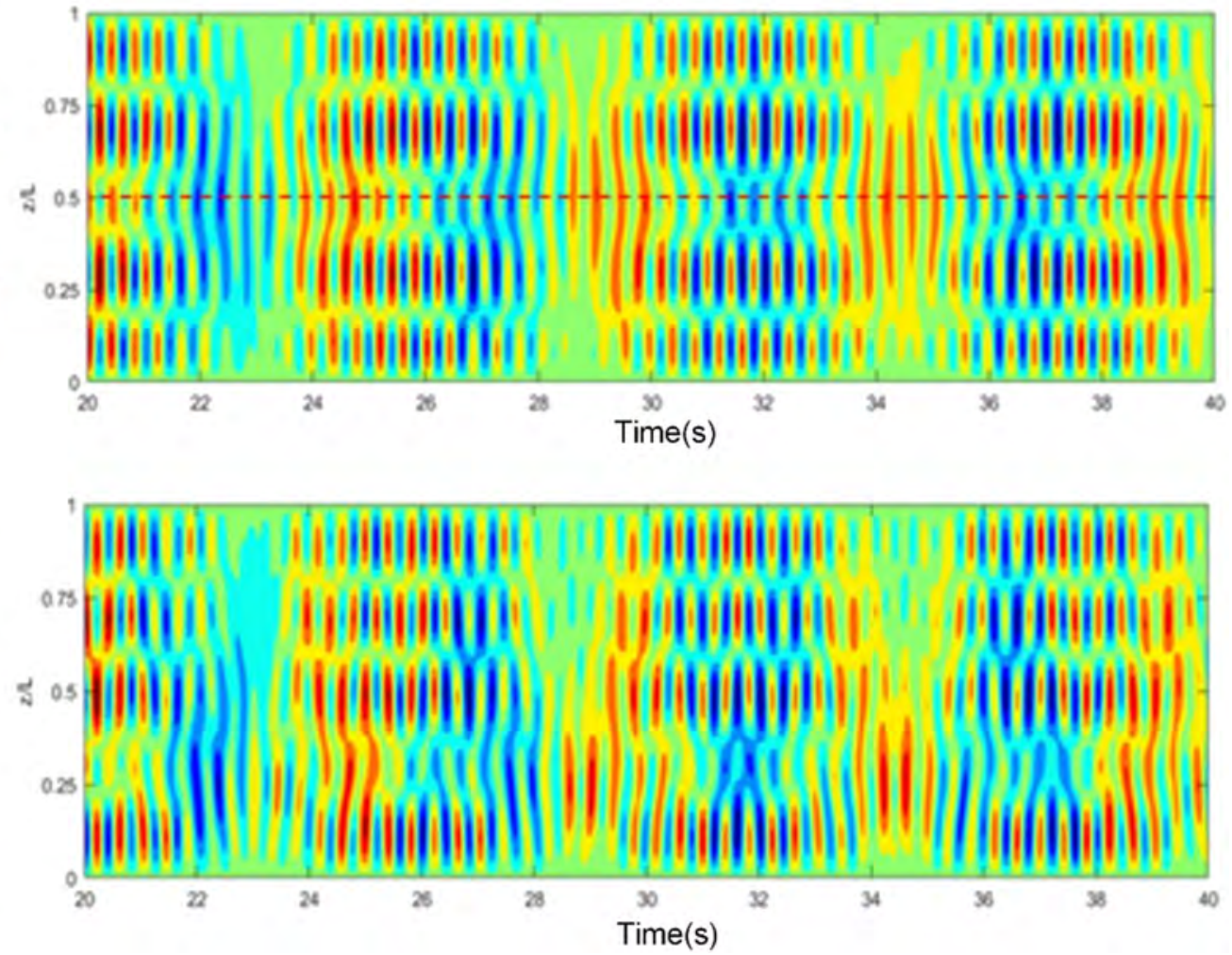

FIG. 15. The flow field position diagram and VIV response spatio-temporal plot of the riser in the corresponding flow field. (a) Upper, (b) middle, and (c) lower. 
TABLE VI. Summary of flow field parameters and vibration response data with different spanwise lengths in the stepped flow field.

\begin{tabular}{lccccc}
\hline \hline Case & $\begin{array}{c}\text { The flow field } \\
\text { length }(\mathrm{m})\end{array}$ & $\begin{array}{c}\text { Amplitude } \\
\text { extreme value }(\mathrm{m})\end{array}$ & $\begin{array}{c}\text { The flow field } \\
\text { location }(\mathrm{m})\end{array}$ & $\begin{array}{c}\text { Extreme RMS } \\
\text { amplitude (m) }\end{array}$ & $\begin{array}{c}\text { Extreme RMS } \\
\text { amplitude location (m) }\end{array}$ \\
\hline 1 & 1 & 0.00117 & 2.4 & 0.0005005 & 2.4 \\
2 & 2 & 0.004095 & 2.3 & 0.001754 & 2.4 \\
3 & 4 & 0.009575 & 2.3 & 0.004163 & 2.3 \\
4 & 6 & 0.007963 & 2.5 & 0.003544 & 2.5 \\
5 & 8 & 0.00513 & 4 & 0.002247 & 4 \\
6 & 10 & 0.005762 & 2.8 & 0.002361 & 3.2 \\
7 & 12 & 0.009827 & 10.2 & 0.00428 & 10.3 \\
8 & 14 & 0.008308 & 10.1 & 0.003569 & 10.4 \\
9 & 16 & 0.006853 & 12.2 & 0.002853 & 12 \\
10 & 18 & 0.008222 & 10.5 & 0.00338 & 10.4 \\
11 & 19 & 0.0105 & 10.4 & 0.004287 & 10.3 \\
12 & 20 & 0.01149 & 10.3 & 0.004722 & \\
\hline \hline
\end{tabular}

field are significantly reduced compared to that in the uniform flow. The result is consistent with the structure and distribution characteristics of the flow field. On the one hand, the energy input of the flow field is halved in the stepped flow field, and the amplitude and frequency of the vibration are naturally reduced. On the other hand, the vortex lift only acts on the upper part of the riser, which can be regarded as the excitation region, and the rest can be regarded as the damping region. The blockage of the damping region further reduces the amplitude and frequency of the VIV response of the riser in the stepped flow field. When the flow velocities are $0.5 \mathrm{~m} / \mathrm{s}$ and $0.8 \mathrm{~m} / \mathrm{s}$, the cross-flow amplitude in the stepped flow field is reduced by about $50 \%$ compared with that in the uniform flow field, while the amplitude is not reduced much when the flow velocity is $0.2 \mathrm{~m} / \mathrm{s}$. Figure 14 shows the frequency spatio-temporal plot of the riser VIV response at different flow velocity in the step flow field. It can be seen that the lock-in vibration of the riser occurs at a flow velocity of $0.2 \mathrm{~m} / \mathrm{s}$ in which the amplitude is much larger than the other two conditions. Hence, the occurrence condition of lock-in vibration is closely related to the velocity, but not to the spanwise length of the flow field.

Figure 15 shows the VIV response of the riser under three kinds of stepped flow fields located at the upper, middle, and lower part of the riser, respectively, of which the flow velocity is $0.5 \mathrm{~m} / \mathrm{s}$ and the spanwise length is $10 \mathrm{~m}$. Comparing the VIV response of these three cases, it can be seen that when the flow field is located in the middle of the riser, the VIV amplitude of the riser is significantly higher than the other two conditions. The VIV exhibits a symmetrical characteristic, and the amplitude extreme point is below the midpoint of the riser, which is similar to the vibration characteristics in the uniform flow field. The reason may be that when the flow field is distributed in the middle of the riser, the blockage effect of the damper region is weaker than the other two working conditions since the flow field is far from the upper and lower ends of the riser, resulting in a large overall amplitude. Besides, the large

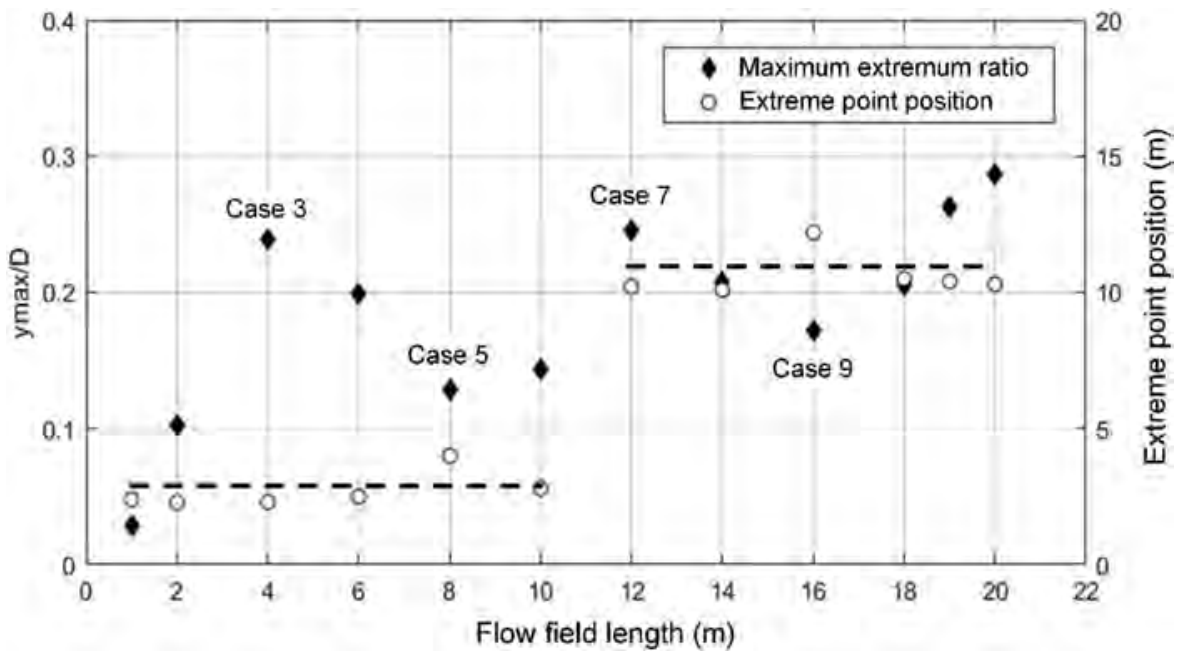

FIG. 16. The scatter plot of amplitude extreme value ratio and position point. 
amplitude tends to appear in the excitation region, while in the damping region, the VIV response fluctuates to decrease as the distance from the excitation region increases. The vortex excitation force generated by the riser due to that the surrounding vortex shedding only acts on the location where the flow field exists. Hence, this part can be regarded as the excitation zone, and the rest can be regarded as the damping zone. The vortex-excited force in the excitation zone will force the riser to generate vortex-induced vibration, while the retardation in the damping zone will reduce the amplitude and frequency of the VIV in the riser at other positions. Therefore, for stepped flow field the position of the flow field affects the location where the riser amplitude is large. However, as the velocity of the flow field is the same, the vibration response of the three cases are consistent in time. The symmetry of the position of the flow field makes the VIV response show a certain symmetry in space. As shown in the figure, the cross-flow displacement spatio-temporal plot of three working conditions is symmetrically distributed with the symmetry axis of the centerline of the flow field in the middle of the riser. In addition, when the flow field is located at the lower part of the riser, since the tension, stiffness, and natural frequency of the riser gradually decrease, it results in a slightly higher vibration mode of the excitation region than when the flow field is located at the upper part of the riser.

Table VI shows the flow field parameters and vibration response data of the model with different spanwise lengths. Among them, the length of the flow field refers to the distance extending underwater along the riser with the water surface as the zero point and the position of the extreme point refers to the distance from the water surface.

Figure 16 shows the scatter diagram of the change trend of the amplitude extreme value ratio and the position points with the length of flow field drawn according to Table VI. It can be seen that the maximum amplitude ratio of each model fluctuating rise with the increase of the length of the flow field. In the stepped flow field, with the increase of the length of the flow field, on the one hand, the energy input of the flow field increases; on the other hand, the range of vortex shedding on the riser increases, that is, the range of vortex-induced lift increases, which will increase the amplitude and frequency of the riser and further increase the intensity of vortexinduced vibration. Since the overall vibration of the riser due to vortex shedding at different flow field lengths is multi-modal, its vibration frequency will sometimes be close to or coincident with the vortex shedding frequency of the riser, resulting in lock-in vibration or different degrees of synchronous vibration, which will cause a sudden increase in the riser amplitude. When the frequency of VIV of the riser is not close to or coincides with its vortex shedding frequency, its amplitude will decrease relatively. Therefore, the intensity of VIV of the riser in the stepped flow field will fluctuate with the increase of the flow field length. Under the same flow velocity, the amplitude of the uniform flow field is higher than that of the stepped flow field; the position of the extreme point is basically stable at around $3 \mathrm{~m}$ and $10.5 \mathrm{~m}$. Therefore, in the stepped flow field, the position of the maximum amplitude point is basically unchanged regardless of the spanwise ratio of the flow field;

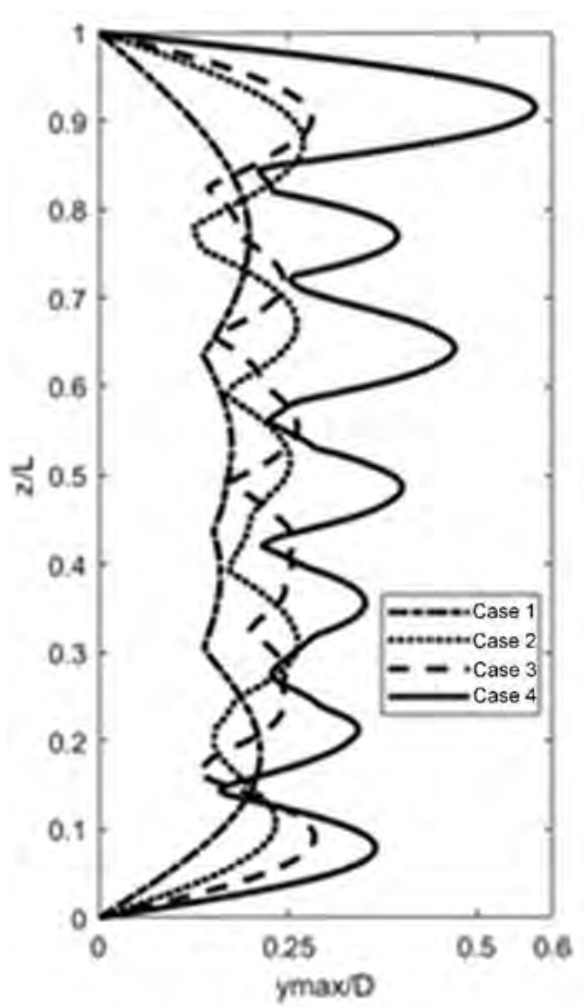

(a)

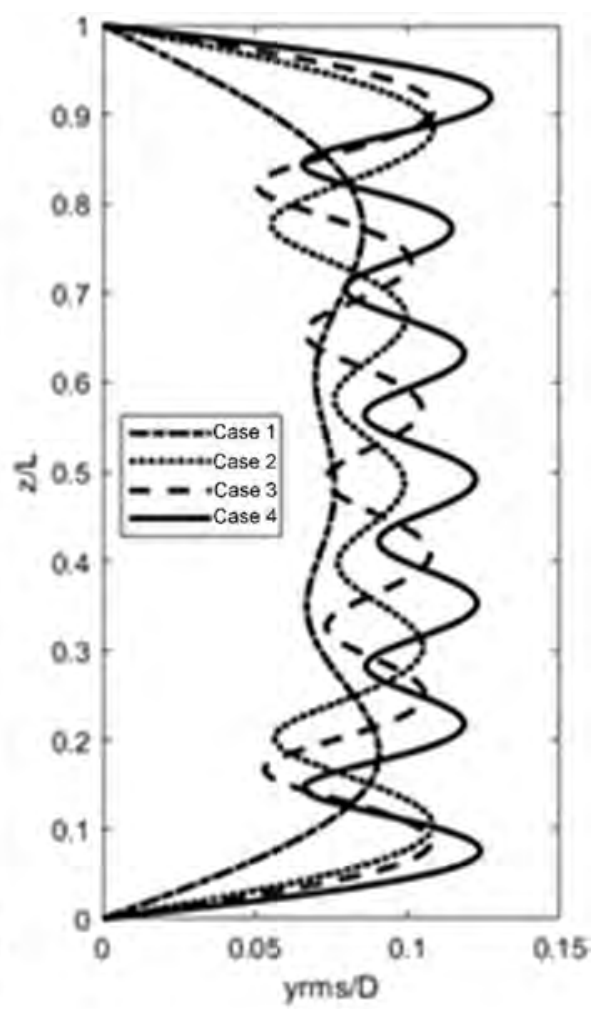

(b)
FIG. 17. The VIV response of the riser in shear flow field with different maximum flow velocities. (a) Amplitude extrema envelope and (b) cross-flow RMS amplitude curve. 
and the increase of the length of the flow field does not necessarily lead to the increase of the vibration amplitude, which increases the difficulty in the prediction and suppression of the VIV of the riser.

\section{Shear flow field}

Figure 17 shows the cross-flow extreme amplitude envelope and RMS amplitude of the VIV response of the top tension riser under four shear flow fields with the maximum flow velocities of $0.2 \mathrm{~m} / \mathrm{s}, 0.5 \mathrm{~m} / \mathrm{s}, 0.8 \mathrm{~m} / \mathrm{s}$, and $1 \mathrm{~m} / \mathrm{s}$. It can be seen that the riser in the shear flow field exhibits different vibration characteristics from the uniform flow field. With the increase of the flow velocity, the amplitude and vibration frequency of the vortex induced lift force increased, resulting in the synchronous increase of the amplitude and mode of VIV of the riser and the vibration range increased in the span of the riser. In the shear flow field, the increase of the flow velocity will increase the pressure difference generated by the vortexes on both sides of the riser and accelerate the frequency of vortex shedding, thus increasing the amplitude and frequency of the vortex-induced lift acting on the riser. In addition, in the shear flow field, the flow velocity and vortex shedding frequency along the riser span are inconsistent. There is no vortex excitation force of uniform size and frequency, which is difficult to cause the lock-in vibration of the riser. That is, the fluctuation VIV intensity caused by the coincidence of the frequency of the vortex excitation force and the natural frequency of the riser does not exist, and so the VIV intensity of the riser in the shear flow increases gradually with the increase of the flow velocity. The amplitude and mode of the riser in the shear flow field are reduced at the same maximum flow velocity compared to that in the uniform flow field. In addition, it can be found from Figs. 17(a) and 17(b) that although the shear flow field profile is asymmetrical, the effective VIV response of the riser shows a certain symmetry, which is inconsistent with the flow field profile, and the vibration mode is the mode shape that is excited by the highest flow velocity.

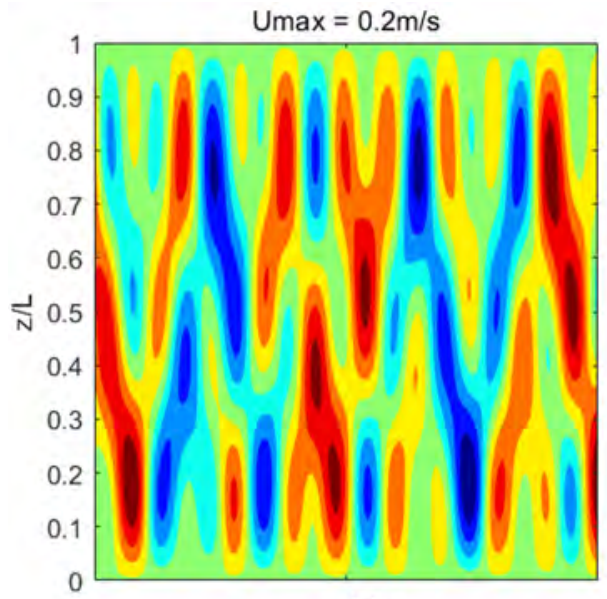

(a)

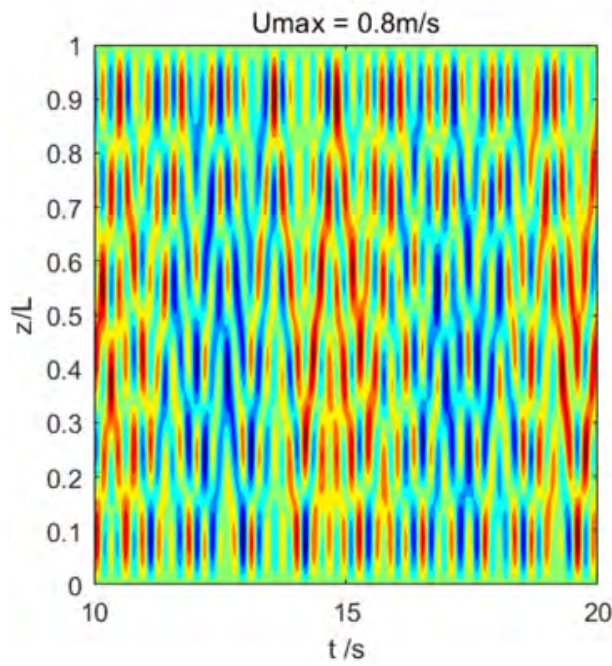

(c)

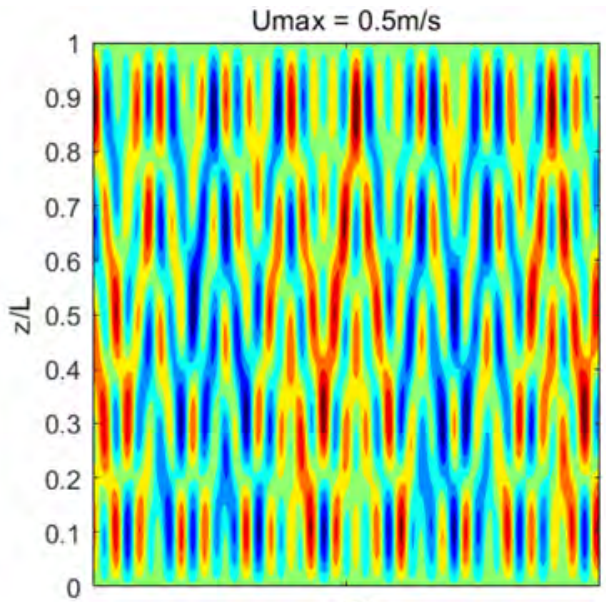

(b)

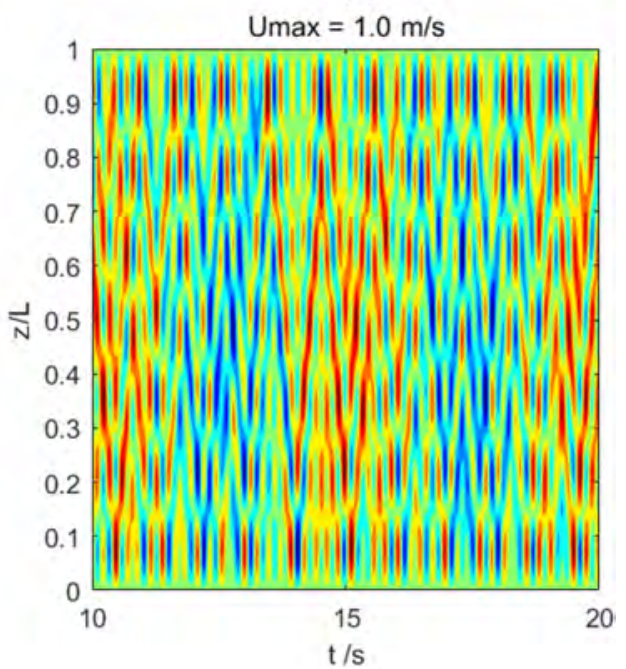

(d)
FIG. 18. The VIV response spatiotemporal plot of the riser in the shear flow with the maximum flow velocities of (a) $0.2 \mathrm{~m} / \mathrm{s}$, (b) $0.5 \mathrm{~m} / \mathrm{s}$, (c) $0.8 \mathrm{~m} / \mathrm{s}$, and (d) $1 \mathrm{~m} / \mathrm{s}$. 
Figure 18 shows the VIV response spatio-temporal plot of the riser in the shear flow with the maximum flow velocities of $0.2 \mathrm{~m} / \mathrm{s}$, $0.5 \mathrm{~m} / \mathrm{s}, 0.8 \mathrm{~m} / \mathrm{s}$, and $1 \mathrm{~m} / \mathrm{s}$. It can be seen that unlike the standing wave characteristic of the VIV response in the uniform flow field, the dynamic VIV response in the shear flow field exhibits a mixing characteristic of the standing and traveling wave. This characteristic changes along the riser span, and the closer to the two end points of the riser, the more obvious the standing wave characteristics are; in the middle of the riser, the vibration wave crest will move back and forth along the riser span. As the flow velocity increases, the vibration responses of the four working conditions show a similarity or inclusion relationship in time and space, which can be regarded as a mapping from the flow field profile to the vortex-induced vibration response. Compared with the uniform flow field, the flow velocities along the riser span in the shear flow field are different, which causes the vortex shedding frequency to change linearly along the riser span. Since the vortex shedding frequency at each point of the riser in the shear flow field is different, it is difficult to excite a wide range of lock-in vibrations or synchronous vibrations. Moreover, there is no lock-in vibration occurring in the shear flow field studied in this paper.

Figures 19-21 show the amplitude curve, VIV response spatiotemporal plot, and spectral characteristics of the riser in the shear flow with the maximum flow velocity of $0.5 \mathrm{~m} / \mathrm{s}$, and the spanwise length of the flow field gradually increasing. The vortex shedding frequency varies linearly from $0 \mathrm{~Hz}$ to $2.5 \mathrm{~Hz}$. It can be seen from
Figs. 19 and 20 that the amplitude of the riser model increased significantly with the increase of the spanwise length of the flow field, and the mixing characteristics of the standing-wave and traveling wave of the vibration response became more and more obvious, which was different from the variation rules of the fluctuation rising in the uniform flow field and the stepped flow field. It can be seen from Fig. 21 that as the spanwise length of the flow field increases, the amplitude of the model increases significantly, while the vibration mode changes little; the vibration frequency changes from broad to concentrated, and the frequency proportion also gradually shifts from low order to high order, resulting in the gradual increase of the vibration intensity. In conclusion, the modal characteristics of the VIV response are mainly affected by the maximum flow velocity, while the amplitude is greatly affected by the flow field length along the riser span. The higher the shear flow velocity, the faster the frequency of the vortex shedding and the frequency of vortex excitation, which can excite the high-order vibration frequency of the riser. The flow velocity of the shear flow field gradually decreases from the top to the bottom, and the vortex shedding frequency also gradually decreases so that the frequency range and composition of the riser vibration increase when the maximum flow velocity increases. When the maximum flow velocity of the shear flow field is constant and the spanwise length increases, the frequency range of the vortex excitation force acting on the riser will generate constant VIV, and the vibration mode of the riser is basically unchanged. However, as the spanwise length increases, on the one hand, the vortex-induced

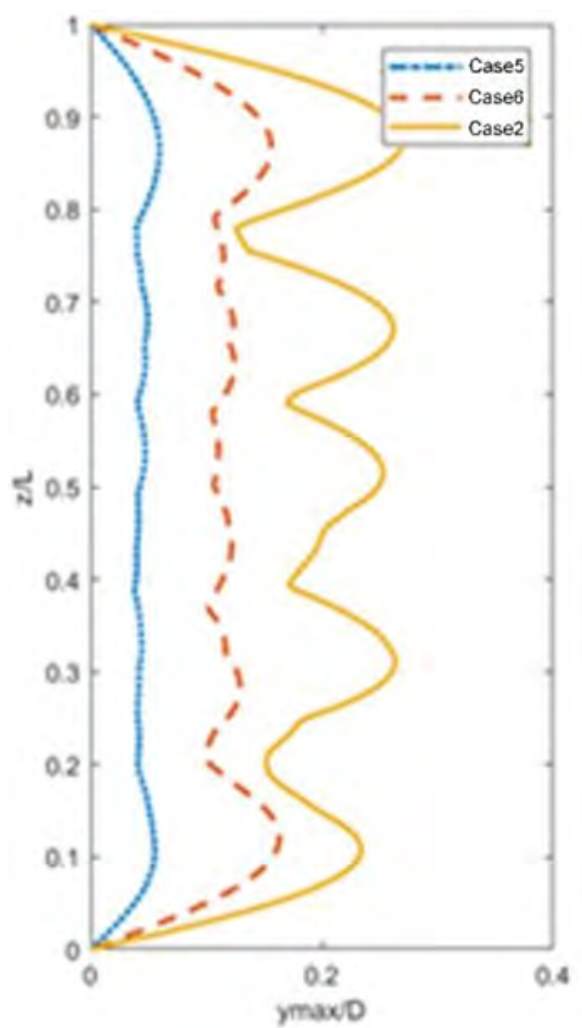

(a)

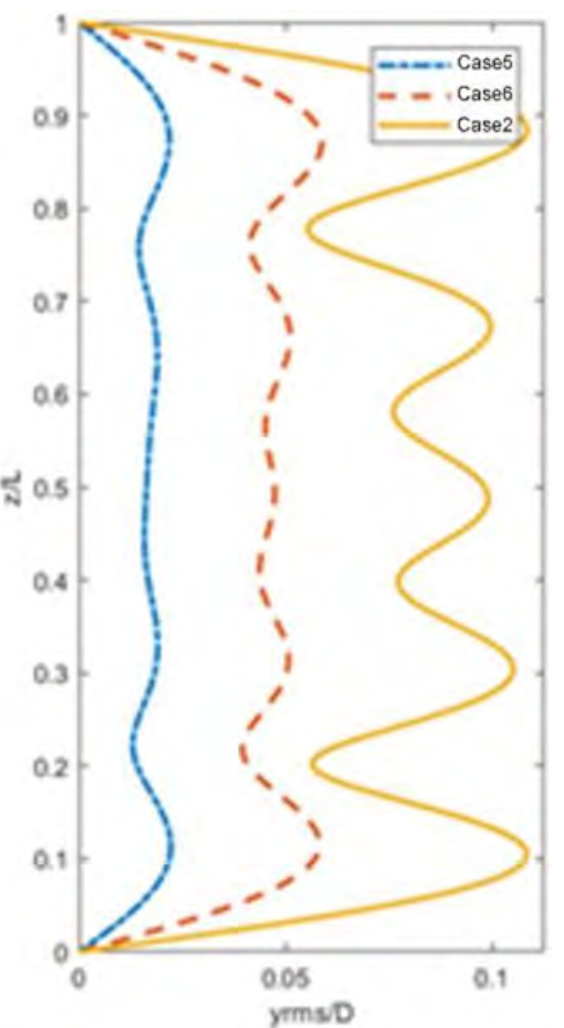

(b)
FIG. 19. The VIV response of the riser in the shear flow with the maximum flow velocity of $0.5 \mathrm{~m} / \mathrm{s}$ and the spanwise length of the flow field gradually increasing. (a) The extreme amplitude curve and (b) the RMS amplitude curve. 


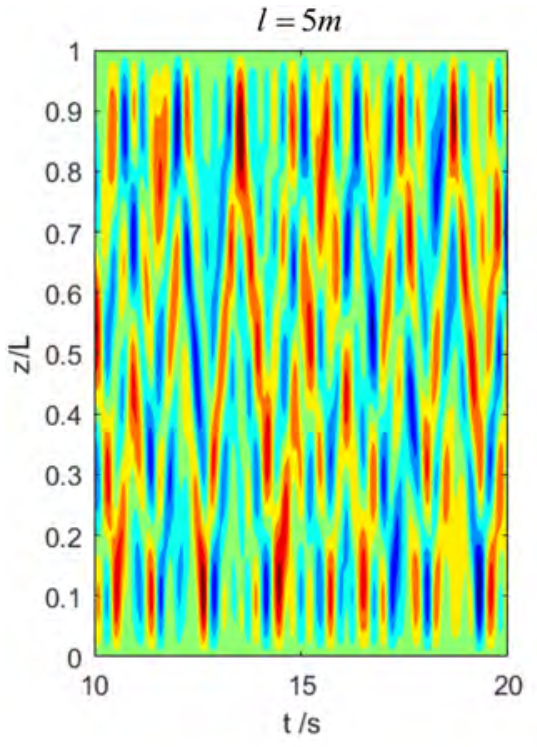

(a)

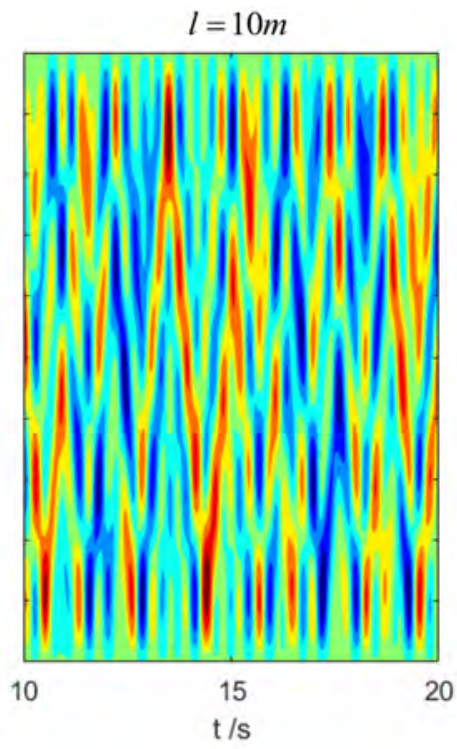

(b)

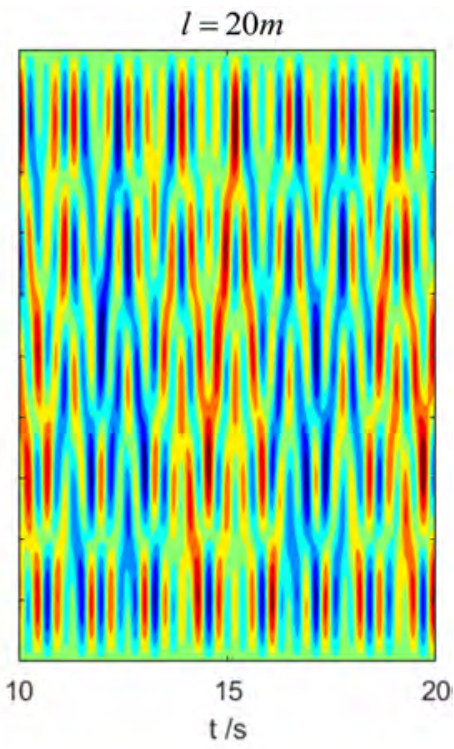

(c)

FIG. 20. The VIV response spatio-temporal plot of the riser in the shear flow with the maximum flow velocity of $0.5 \mathrm{~m} / \mathrm{s}$ and different span lengths of the flow field. (a) $I=5 \mathrm{~m}$, (b) $I=10 \mathrm{~m}$, and (c) $I=20 \mathrm{~m}$.

lift of the riser increases and, on the other hand, the energy input into the VIV system of the riser increases so that the amplitude of the riser increases significantly when the vibration mode is basically unchanged.

Figure 22 shows the RMS amplitude curve and the vibration spatio-temporal plot of the VIV response of the riser when the flow velocity and the spanwise length of flow field increase simultaneously. It can be seen that if the slope of shear flow field remains unchanged, the VIV intensity of the riser will increase with the increase of the velocity and spanwise proportion of the flow field. The increase of the flow velocity or spanwise proportion of the shear flow field will excite a strong VIV response, and the synchronous

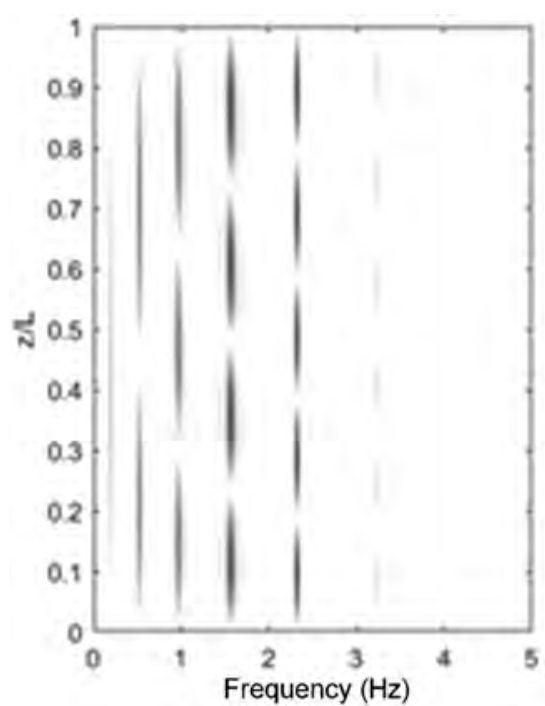

(a)

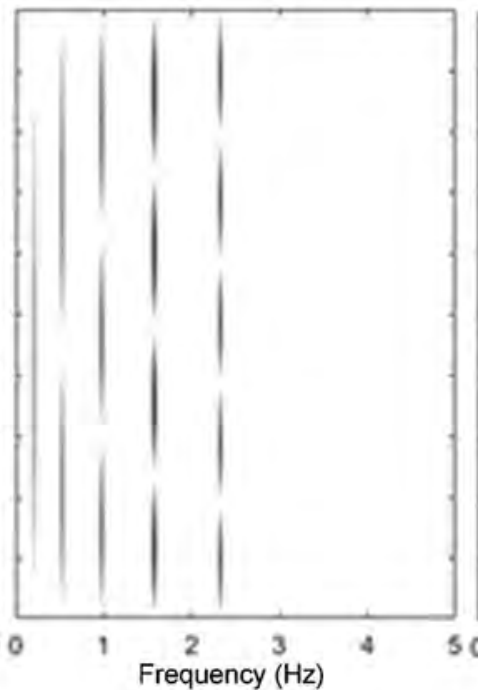

(b)

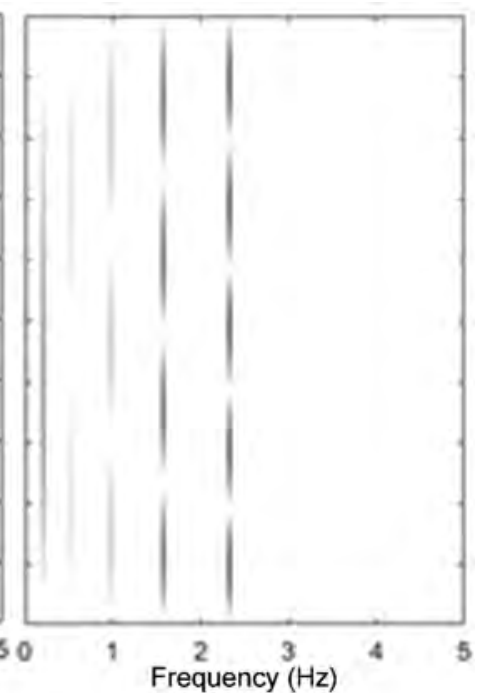

(c)

FIG. 21. The frequency spatio-temporal plot of the riser in the shear flow with the maximum flow velocity of $0.5 \mathrm{~m} / \mathrm{s}$ and different $\mathrm{span}$ lengths of the flow field. (a) $I=5 \mathrm{~m}$, (b) $I=10 \mathrm{~m}$, and $(\mathrm{c}) I=20 \mathrm{~m}$. 


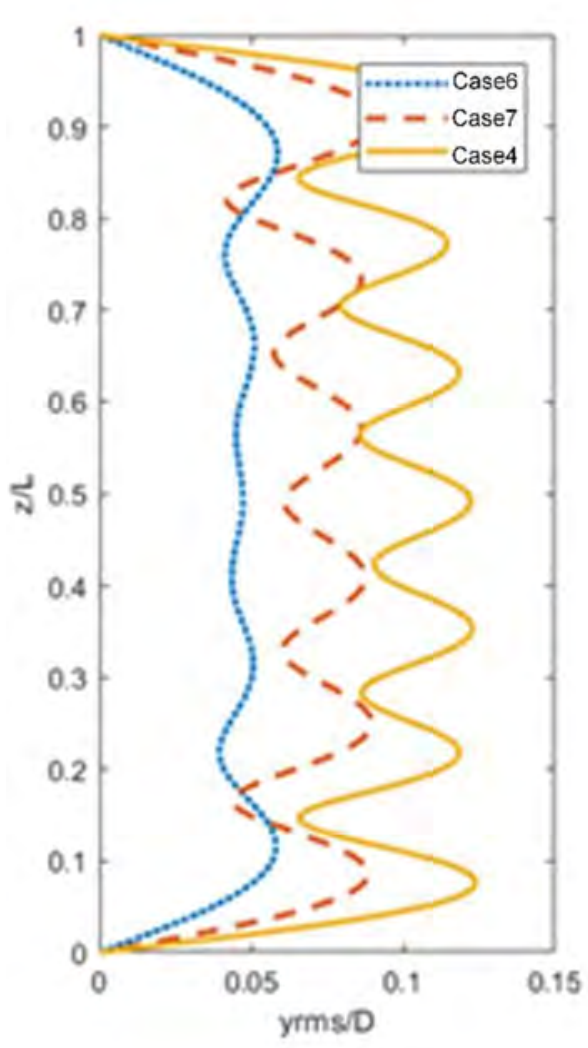

(a)
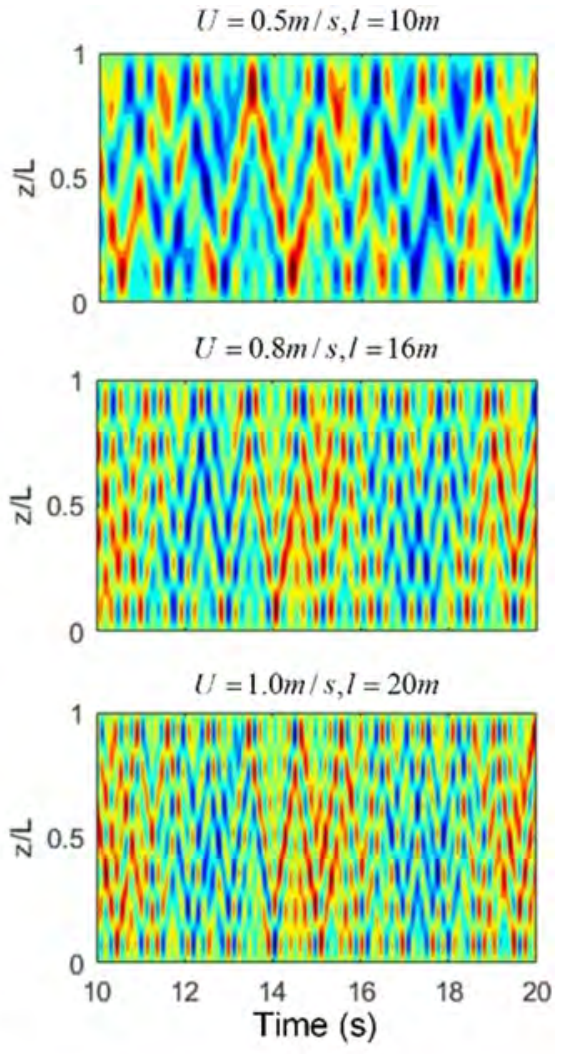

FIG. 22. VIV response of the riser when the flow velocity and the spanwise length of shear flow field increase simultaneously. (a) The RMS amplitude curve, and (b) the VIV response spatio-temporal plot. increase of the two will increase the modal and amplitude response of the riser simultaneously.

\section{Composite flow field}

Figures 23(a) and 23(b) show the cross-flow RMS amplitude curve of VIV of the riser in the composite flow field superimposed in the forward direction. It can be seen that the vibration characteristics of the riser in this composite flow field are similar to that in the shear flow field. As the flow velocity increases, the amplitude and the frequency synchronization increases. Figure 23(c) shows the vibration response the spatio-temporal plot. It can be seen that, in the low-velocity phase, the VIV response exhibits the mixing characteristics of the standing wave and traveling wave, which is similar to that in the shear flow field. With the increase of the flow velocity, the spatio-temporal plot of the VIV response is completely characterized by standing waves, and a periodic phase change occurs, which is similar to the vibration characteristics in the uniform flow field. Moreover, it can be seen that the traveling wave and standing wave responses of the riser model are related to the difference between the highest and the lowest velocities. When the overall flow velocity of the superimposed composite flow field is low, the difference between the maximum and the minimum flow velocities is large; so it makes the VIV response of the riser closer to the (b) shear flow field. Because the flow velocity of the shear flow field and the frequency of the vortex shedding vary greatly along the riser span, it is difficult to form a stable standing wave. When the overall flow velocity of the composite flow field is large, the difference between the maximum and minimum flow rates becomes small if compared to the entire flow field so that the corresponding VIV response characteristics are closer to a uniform flow field. The flow velocity and the relative vortex shedding frequency difference along the riser span decreases and the standing wave characteristic appears.

Figure 24 shows the vibration frequency spectrum plot of the riser in the forward superimposed composite flow field. It can be seen that the main frequency component of the riser model is still dominated by the natural frequency, and no lock-in vibration is observed. The vortex shedding frequency corresponding to the three composite flow in this section are $(2.5-1) \mathrm{Hz},(4-2.5) \mathrm{Hz}$, and (5-3.5) Hz, respectively, as shown in the red dotted box in the figures. It can be seen that although the riser does not occur obvious synchronous vibration, the dominant frequency of VIV of the riser model is generally dominated by the natural frequency within the vortex shedding frequency range.

Figure 25 shows the RMS amplitude map, spatio-temporal plot, and frequency spectrum of VIV response of the riser in the spanwise superimposed composite flow field. It can be seen from Fig. 25(a) 


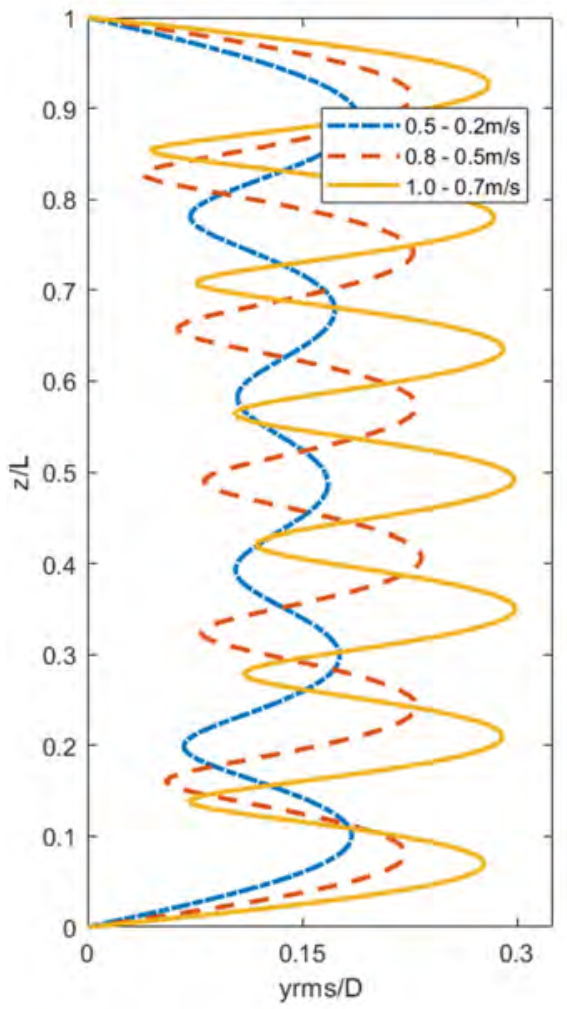

(a)

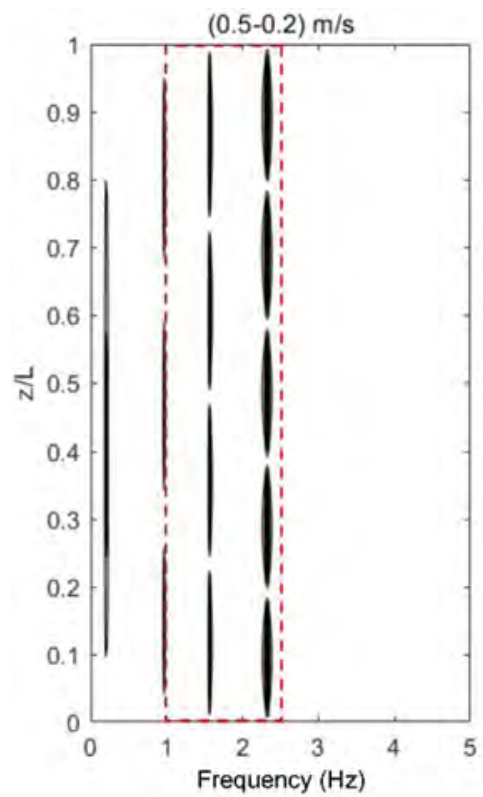

(a)
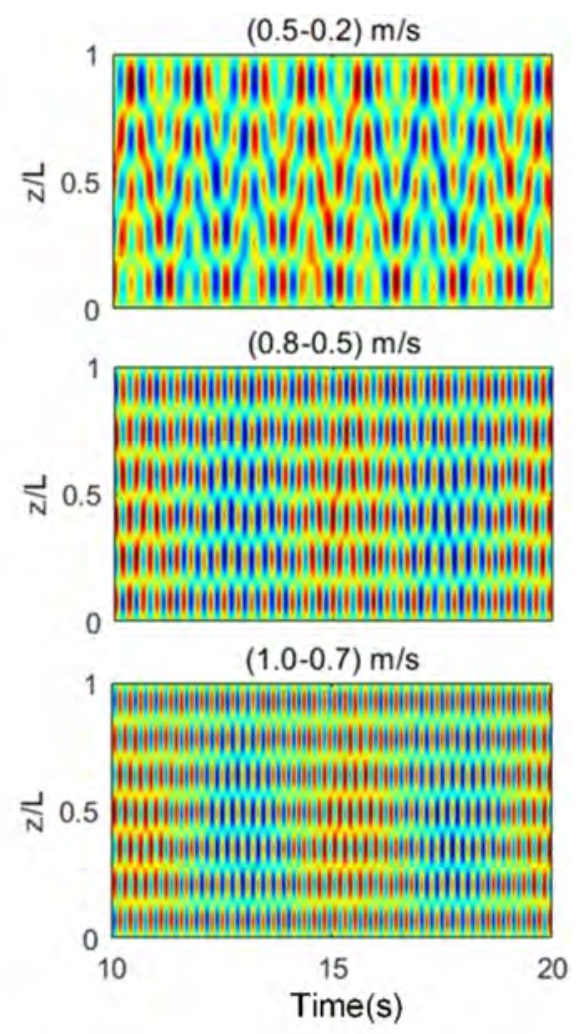

(b)
FIG. 23. VIV response of the riser in a forward superimposed flow field. (a) RMS amplitude curve; (b) VIV response spatio-temporal plot.

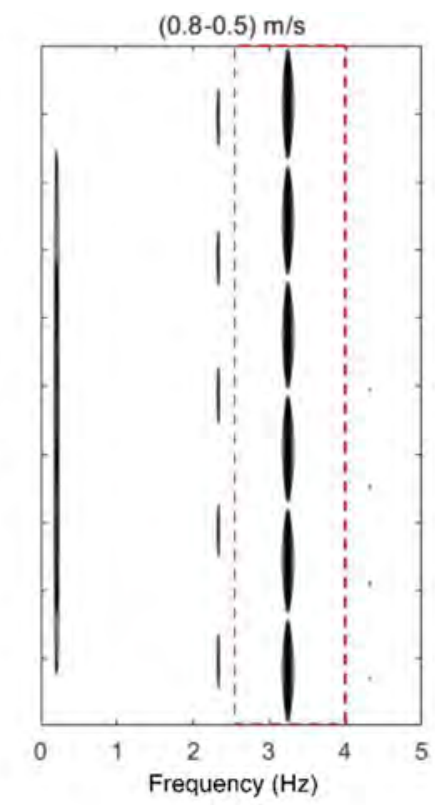

(b)

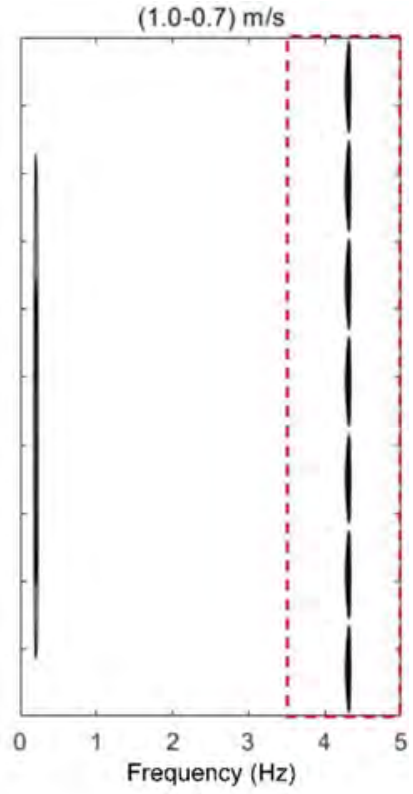

(c)

FIG. 24. The vibration frequency spectrum plot of the riser in the forward superimposed composite flow field. The flow velocity of (a) $(0.5-0.2) \mathrm{m} / \mathrm{s},(\mathrm{b})(0.8-0.5) \mathrm{m} / \mathrm{s}$, and (c) $(1.0-0.7) \mathrm{m} / \mathrm{s}$. 


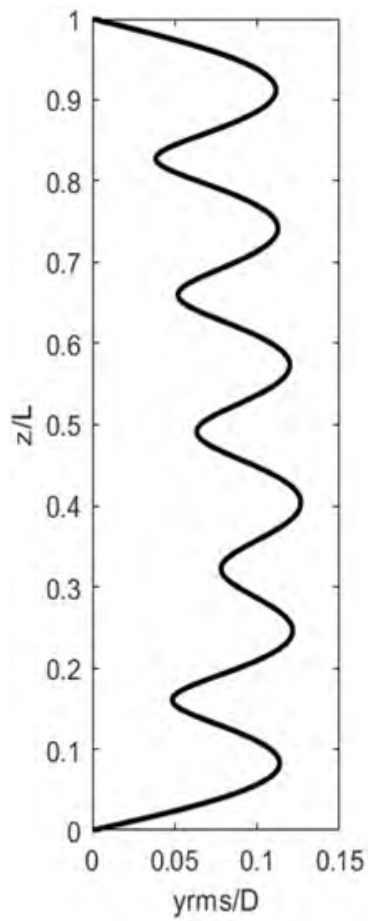

(a)

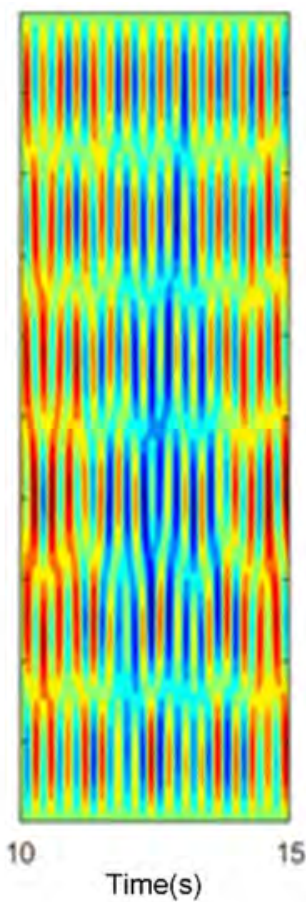

(b)

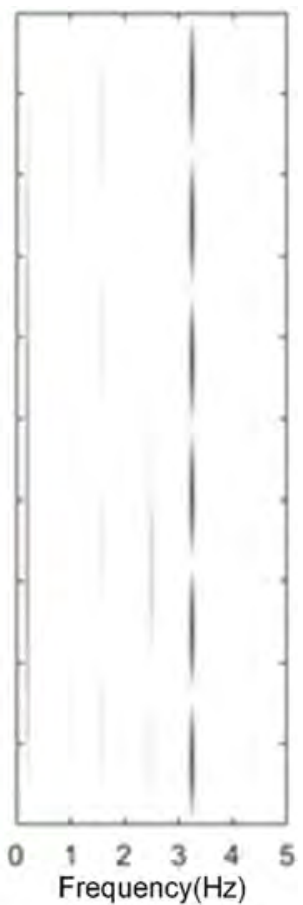

(c)
FIG. 25. VIV response of the riser in a forward superimposed flow field. (a) The cross-flow RMS amplitude curve, (b) the VIV response spatio-temporal plot, and (c) the vibration frequency spectrum plot. that the effective mode and the dominant mode is the sixth-order natural frequency during the vibration process of the model. As the flow velocity decreases from top to bottom, the VIV amplitude exhibits a relatively stable change, and no lock-in vibration occurs. The position of the maximum RMS vibration amplitude appears at the position of the stepped flow field profile, reaching $0.13 \mathrm{D}$. Hence, in the superimposed flow field profile, the stepped flow field has a greater influence on the maximum amplitude of the riser. The vibration response exhibits the mixing characteristics of standing wave and traveling wave, in which the standing wave characteristics are relatively large. Besides, there is obvious traveling wave characteristics and modal transitions observed in the part of the stepped flow field, as shown in Fig. 24(b). In addition, although there is no unified vortex shedding frequency in the spanwise superimposed composite flow field, the overall vortex shedding frequency on the riser is in the range of $0-4 \mathrm{~Hz}$. It can be seen from Fig. 24(c) that the dominant frequency of the riser vibration is in the range of $3-4 \mathrm{~Hz}$, and the natural frequency within the range of vortex shedding frequency is also the dominant frequency.

\section{CONCLUSION}

In this paper, the cross-flow VIV response of a top tension riser under different flow field profile is comprehensively studied using a numerical simulation model based on time domain analysis. The research is mainly carried out in four flow fields: uniform flow field, stepped flow field, shear flow field and composite flow field. First, a semi-empirical time-domain analysis model is proposed in which the fluid-structure interaction problem in the riser vibration process is considered. Second, the proposed numerical model was used to simulate the experimental model in a stepped flow field, and the numerical simulation results were compared with the experimental data to verify the proposed numerical model. The results show that the numerical simulation results of the riser and the experimental results are consistent in response amplitude and frequency, so the proposed numerical simulation model can be applied to the VIV simulation of the steady flow field. Finally, this paper conducted a comprehensive study on the VIV of the top tension riser in the uniform flow field profile, stepped flow field profile, shear flow field profile, and composite flow field profile. The influence of the flow velocity, spanwise length, and other factors of the flow field on the VIV amplitude and frequency characteristics of the riser are studied in detail. The main conclusions obtained in this paper are summarized as follows:

(1) The VIV response of the riser exhibits obvious multi-modal characteristics, which are accompanied by modal transition, lock-in vibration, synchronous vibration, etc., and the region where the lock-in or synchronous vibration occurs is the region where the peak of the mode curve is located. The variation of the flow field profile exhibits a nonlinear relationship with the VIV response.

(2) The VIV intensity of the riser in the uniform flow field shows a tendency of fluctuation rising with the increase of the flow velocity. The vortex shedding frequency has a great influence on the position and amplitude of the maximum amplitude value. The low order frequency, especially the 
first order natural frequency, is decisive for the minimum amplitude.

(3) In the stepped flow field, the increase in the flow velocity and spanwise length will cause the fluctuation rising of the VIV intensity. The flow velocity is the most important factor affecting the VIV response of the riser, controlling the frequency and amplitude of the VIV response. The position of the flow field mainly affects the location where the riser amplitude is large.

(4) The VIV response of the riser in the shear flow field exhibits different properties from the uniform flow field and the stepped flow field, which is mainly reflected in the positive correlation between the flow field profile and the VIV intensity. The increase in the maximum flow velocity and the span proportion increases the vibration intensity, which affects the composition ratio of the vibration frequency and vibration amplitude, respectively. The inclusion relationship of the flow field profile is mapped to the VIV response of the riser so that the vibration response under different working conditions shows a certain similarity. In addition, there is no lockin vibration observed in the shear flow field that is studied in this paper.

(5) The VIV response of the riser in the composite flow field profile has a certain similarity with that in the simple flow field. As the flow field increases, the VIV amplitude and frequency also increase, and the main vibration frequency is dominated by the natural frequency within the vortex shedding frequency range.

In addition, there are still many deficiencies in the paper to be improved and solved. In this paper, the cross-flow VIV of the top tension riser under different flow field profiles is studied. The VIV characteristics of the cross-flow and in-line coupled vibrations need to be studied later. Although the VIV characteristics of many flow field profiles are studied in this paper, these flow fields are all constant flow fields. However, the flow field in actual sea conditions is complex and time-varying, so it is necessary to carry out related research on time-varying flow fields.

\section{ACKNOWLEDGMENTS}

This work was supported by the National Nature Science Foundation of China (Grant No. 51175485), Taishan Scholar (Grant No. tsqn201812025), Fundamental Research project of Central Universities (Grant No. 201941008), Applied Fundamental Research project of Tsingdao (19-9-1-14-jch), Australia Research Council (DE190100931).

\section{REFERENCES}

${ }^{1}$ Z. Yan, B. Liang, G. Wu, S. Wang, and P. Li, "Ultra-long return level estimation of extreme wind speed based on the deductive method," Ocean Eng. 197, 106900 (2020).

${ }^{2}$ G. R. Franzini, A. L. C. Fujarra, J. R. Meneghini, I. Korkischko, and R. Franciss, "Experimental investigation of Vortex-Induced Vibration on rigid, smooth and inclined cylinders," J. Fluids Struct. 25, 742 (2009).

${ }^{3}$ P. W. Bearman, "Vortex shedding from oscillating bluff body," Annu. Rev. Fluid Mech. 16, 195 (1984).

${ }^{4}$ C. H. K. Williamson and R. Govardhan, "Vortex-induced vibrations," Annu. Rev. Fluid Mech. 36, 413 (2004).
${ }^{5}$ C. H. K. Williamson and R. Govardhan, "A brief review of recent results in vortex-induced vibrations,” J. Wind Eng. Ind. Aerodyn. 96, 713 (2008).

${ }^{6}$ R. D. Gabbai and H. Benaroya, "An overview of modeling and experiments of vortex-induced vibration of circular cylinders," J. Sound Vib. 282, 575 (2005).

${ }^{7}$ H. Xue, W. Tang, and X. Qu, "Prediction and analysis of fatigue damage due to cross-flow and in-line VIV for marine risers in non-uniform current," Ocean Eng. 83, 52 (2014)

${ }^{8}$ K. S. Hong and U. H. Shah, "Vortex-induced vibrations and control of marine risers: A review,” Ocean Eng. 152, 300 (2018).

${ }^{9}$ G. Liu, H. Li, Z. Qiu, D. Leng, Z. Li, and W. Li, "A mini review of recent progress on vortex-induced vibrations of marine risers,” Ocean Eng. 195, 106704 (2020).

${ }^{10}$ P. Liu, Y. Liu, X. Wei, C. Xin, Q. Sun, and X. Wu, "Performance analysis and optimal design based on dynamic characteristics for pressure compensated subsea all-electric valve actuator,” Ocean Eng. 191, 106568 (2019).

${ }^{11}$ L. Song, S. Fu, J. Cao, L. Ma, and J. Wu, "An investigation into the hydrodynamics of a flexible riser undergoing vortex-induced vibration," J. Fluids Struct. 63, 325 (2016).

${ }^{12}$ G. Riches, R. Martinuzzi, and C. Morton, "Proper orthogonal decomposition analysis of a circular cylinder undergoing vortex-induced vibrations," Phys. Fluids 30, 105103 (2018).

${ }^{13}$ V. Azadeh-Ranjbar, N. Elvin, and Y. Andreopoulos, "Vortex-induced vibration of finite-length circular cylinders with spanwise free-ends: Broadening the lock-in envelope," Phys. Fluids 30, 105104 (2018).

${ }^{14} \mathrm{~S}$. Fu, J. Wang, R. Baarholm, J. Wu, and C. M. Larsen, "Features of vortexinduced vibration in oscillatory flow," J. Offshore Mech. Arct. Eng. 136(1), 011801 (2013).

${ }^{15}$ A. D. Trim, H. Braaten, H. Lie, and M. A. Tognarelli, "Experimental investigation of vortex-induced vibration of long marine risers," J. Fluids Struct. 21, 335 (2005).

${ }^{16} \mathrm{H}$. Lie and K. E. Kaasen, "Modal analysis of measurements from a large-scale VIV model test of a riser in linearly sheared flow," J. Fluids Struct. 22, 557 (2006).

${ }^{17}$ J. R. Chaplin, P. W. Bearman, F. J. Huera Huarte, and R. J. Pattenden, "Laboratory measurements of vortex-induced vibrations of a vertical tension riser in a stepped current," J. Fluids Struct. 21, 3 (2005).

${ }^{18}$ J. Gu, M. Vitola, J. Coelho, W. Pinto, M. Duan, and C. Levi, “An experimental investigation by towing tank on VIV of a long flexible cylinder for deepwater riser application," J. Mar. Sci. Technol. 18, 358 (2013).

${ }^{19}$ F. J. Huera-Huarte, Z. A. Bangash, and L. M. González, "Towing tank experiments on the vortex-induced vibrations of low mass ratio long flexible cylinders," J. Fluids Struct. 48, 81 (2014).

${ }^{20} \mathrm{~N}$. Srinil, "Multi-mode interactions in vortex-induced vibrations of flexible curved/straight structures with geometric nonlinearities," J. Fluids Struct. 26, 1098 (2010).

${ }^{21}$ N. Srinil, "Analysis and prediction of vortex-induced vibrations of variabletension vertical risers in linearly sheared currents," Appl. Ocean Res. 33, 41 (2011).

${ }^{22}$ M. J. Thorsen, S. Sævik, and C. M. Larsen, "Non-linear time domain analysis of cross-flow vortex-induced vibrations," Mar. Struct. 51, 134 (2017).

${ }^{23}$ P. Liu, Y. Liu, Z. Huang, B. Cai, Q. Sun, X. Wei, and C. Xin, “Design optimization for subsea gate valve based on combined analyses of fluid characteristics and sensitivity,” J. Pet. Sci. Eng. 182, 106277 (2019).

${ }^{24}$ C. Ji, Y. Cui, D. Xu, X. Yang, and N. Srinil, "Vortex-induced vibrations of dualstep cylinders with different diameter ratios in laminar flows," Phys. Fluids 31, 073602 (2019).

${ }^{25}$ F. A. González Cornejo, M. A. Cruchaga, and D. J. Celentano, "Modelling low Reynolds number vortexinduced vibration problems with a fixed mesh fluid-solid interaction formulation," Phys. Fluids 29, 113601 (2017).

${ }^{26} \mathrm{~K}$. Herfjord, S. O. Drange, and T. Kvamsdal, "Assessment of vortex-induced vibrations on deepwater risers by considering fluid-structure interaction," J. Offshore Mech. Arct. Eng. 121, 207 (1999).

${ }^{27}$ Y. Duanmu, L. Zou, and D. Wan, "Numerical analysis of multi-modal vibrations of a vertical riser in step currents," Ocean Eng. 152, 428 (2018).

${ }^{28}$ B. Fu, L. Zou, and D. Wan, "Numerical study of vortex-induced vibrations of a flexible cylinder in an oscillatory flow," J. Fluids Struct. 77, 170 (2018). 
${ }^{29}$ L. Sun, Z. Zong, J. Dong, G. H. Dong, and C. F. Liu, "Stripwise discrete vortex method for VIV analysis of flexible risers," J. Fluids Struct. 35, 21 (2012).

${ }^{30}$ J. J. Gu, C. An, C. Levi, and J. Su, "Prediction of vortex-induced vibration of long flexible cylinders modeled by a coupled nonlinear oscillator: Integral transform solution," J. Hydrodyn. 24, 888 (2012).

${ }^{31}$ F. J. Huera Huarte, P. W. Bearman, and J. R. Chaplin, "On the force distribution along the axis of a flexible circular cylinder undergoing multi-mode vortex-induced vibrations," J. Fluids Struct. 22, 897 (2006).

${ }^{32} \mathrm{H}$. H. Lin and Y. Y. Wang, "Vortex-induced vibration and dynamic response of marine risers," J. Harbin Eng. Univ. 29, 121 (2008).

${ }^{33}$ M. J. Thorsen, S. Sævik, and C. M. Larsen, "A simplified method for time domain simulation of cross-flow vortex-induced vibrations," J. Fluids Struct. 49, 135 (2014).
${ }^{34}$ M. J. Thorsen, S. Sævik, and C. M. Larsen, "Fatigue damage from time domain simulation of combined in-line and cross-flow vortex-induced vibrations," Mar. Struct. 41, 200 (2015).

${ }^{35}$ M. J. Thorsen, S. Sævik, and C. M. Larsen, "Time domain simulation of vortexinduced vibrations in stationary and oscillating flows," J. Fluids Struct. 61, 1 (2016).

${ }^{36} \mathrm{~J}$. Liu and W. Huang, "A nonlinear vortex induced vibration model of marine risers," J. Ocean Univ. China 12, 32 (2013).

${ }^{37}$ Y. Duanmu, L. Zou, and D.-c. Wan, "Numerical simulations of vortex-induced vibrations of a flexible riser with different aspect ratiosin uniform and shear currents," J. Hydrodyn. 29, 1010 (2017).

${ }^{38}$ MATLAB 7.13, Computer Software, The MathWorks Inc., Natick, USA, 2011. 